\title{
Effect of us 1 gene mutation on pseudorabies virus gene expression
}

\author{
PhD thesis
}

Irma Takacs

Supervisor: ZsoltBoldogkői

Department of Medical Biology

University of Szeged

Szeged, Hungary

2014 


\section{LIST OF PUBLICATIONS}

List of full papers directly related to the subject of the thesis:

I. Takács IF, Tombácz D, Berta B, Prazsák I, Póka N, Boldogkoi Z

The ICP22 protein selectively modifies the transcription of different kinetic classes of pseudorabies virus genes

BMC MOLECULAR BIOLOGY 14: pp. 1-12. (2013)

IF: 2.796

II.Boldogkoi Z, Balint K, Awatramani GB, Balya D, Busskamp V, Viney TJ, Lagali PS, Duebel J, Pasti E, Tombacz D, Toth JS, Takacs IF, Scherf BG, Roska B

Genetically timed, activity-sensor and rainbow transsynaptic viral tools

NATURE METHODS 6:(2) pp. 127-130. (2009)

IF: 16.874

III. Toth JS, Tombacz D, Takacs IF, Boldogkoi Z

The effects of viral load on pseudorabies virus gene expression

BMC MICROBIOLOGY 10: pp. 1-11. (2010)

IF: 2.960

List of full papers directly related to the subject of the thesis:

Aguilar-Valles A, Vaissiere T, Griggs EM, Mikaelsson MA, Takacs IF, Young EJ, Rumbaugh G, Miller CA

Methamphetamine-Associated Memory Is Regulated by a Writer and an Eraser of Permissive Histone Methylation.

BIOLOGICAL PSYCHIATRY (ISSN: 0006-3223) (2013)

IF: 9.247 
Cummulative impact factor: 31.877

Total citations: 48

Independent citations: 33

Oral presentations:

Investigations on the transcription patterns of Aujeszky disease virus mutants

DóraTombácz, JuditTóth, Irma Takács, ZsoltBoldogkői

Congress of Hungarian Association of Microbiology, 2010

Poster presentations:

Effect of insertion mutation of us lgeneonpseudorabiesvirus gene expression

Irma F. Takács, Beáta Berta, István Prazsák, Nándor Póka, Judit S. Tóth, Dóra Tombácz and Zsolt Boldogköi 15th Annual Meeting of the ESCV, 2012, Madrid, Spain

Tombácz D, Tóth JS, Takács IF, Boldogkői Z: Global analysisof pseudorabiesvirusgeneexpressionby RT-PCR. AdvancesInGenomicsSymposium, 2010, Ghent, Belgium

Tombácz D, Pásti E, Takács I, Bálint K, Roska B, Tóth J, Boldogkői Z: Development of pseudorabiesvirus-basedtranssynapticgenedeliveryvectors. 15th International Congress of Hungarian Society forMicrobiology 


\section{Table of Contents}

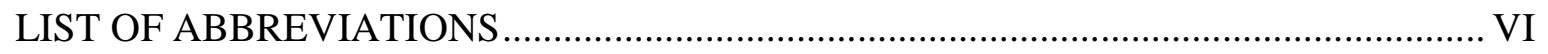

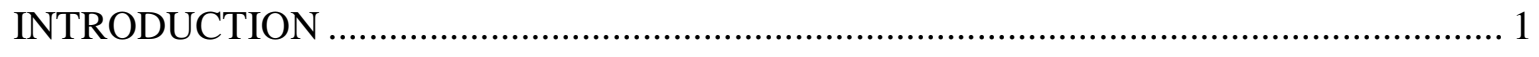

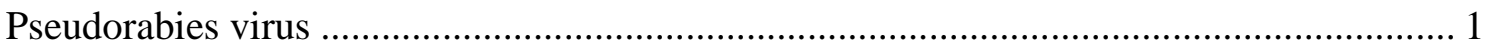

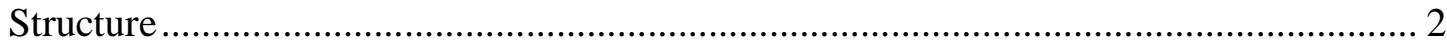

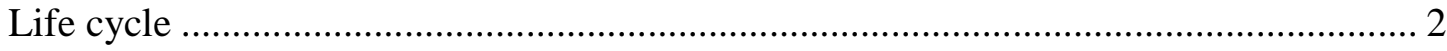

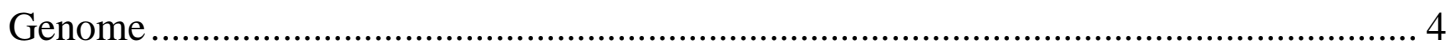

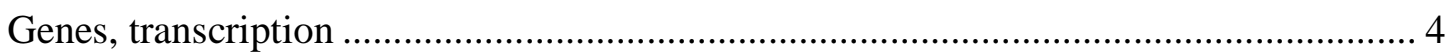

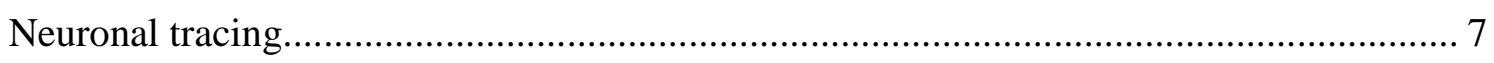

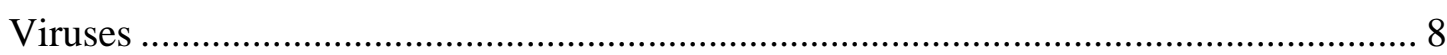

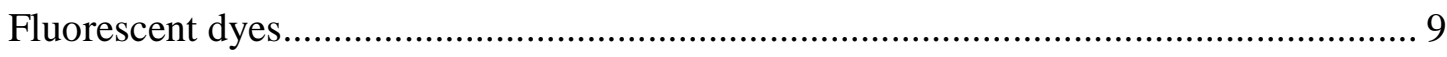

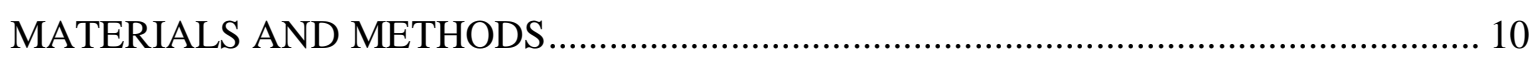

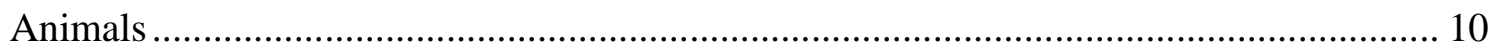

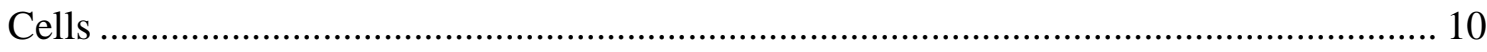

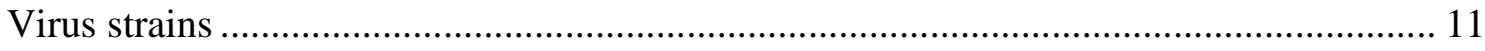

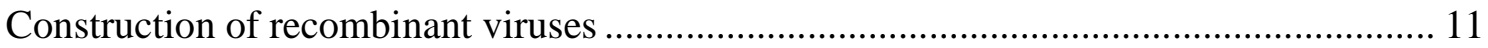

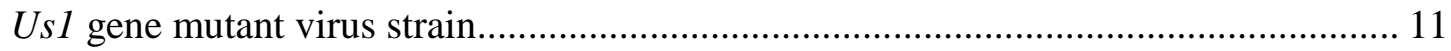

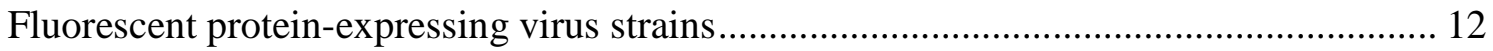

Transfection, generation and isolation of recombinant viruses ....................................... 12

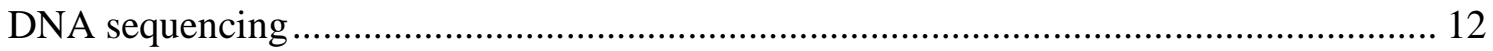

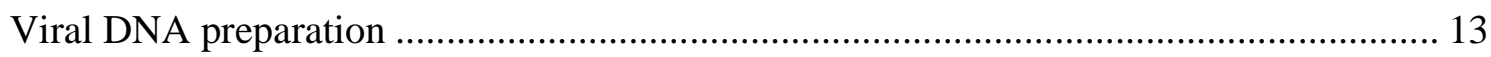

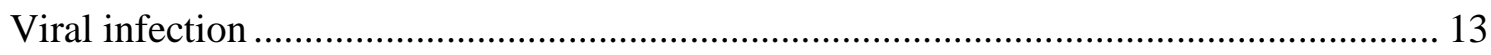

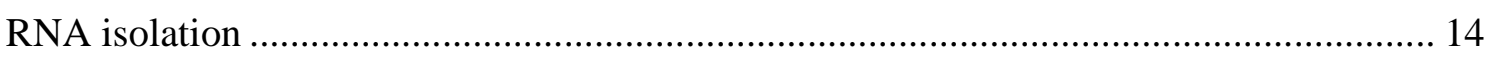

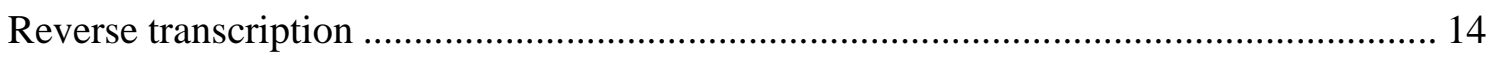

Primers for reverse transcription (RT) and polymerase chain reaction (PCR) .................. 15

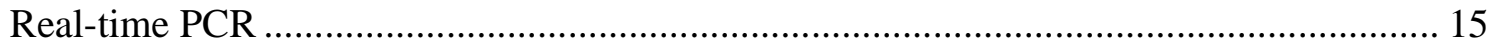

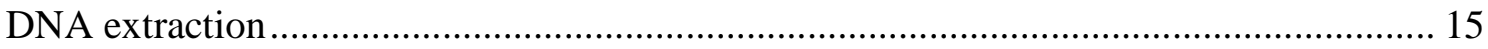

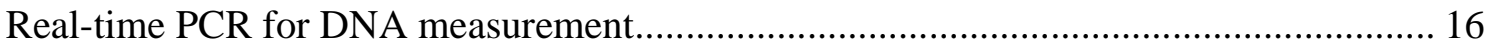




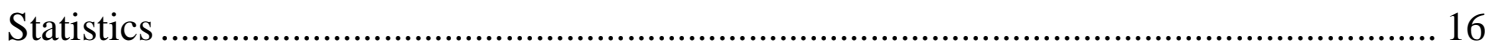

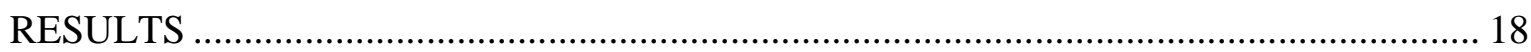

Us1 gene mutation exerts significant effect on gene expression and DNA replication...... 18

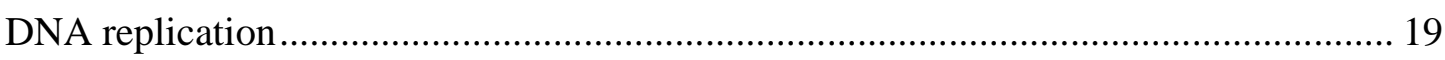

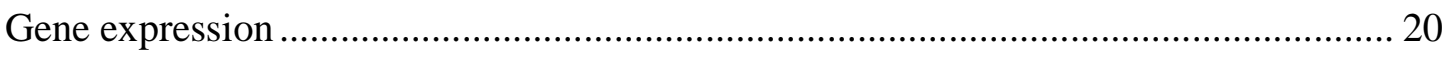

Study of different viral loads on gene expression in wild-type virus ............................... 31

Neuronal labeling with recombinant pseudorabies virus ................................................... 39

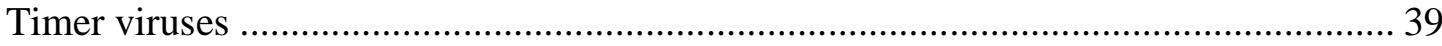

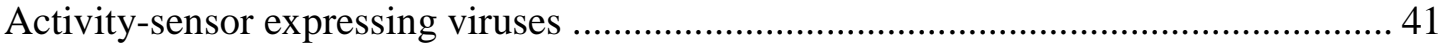

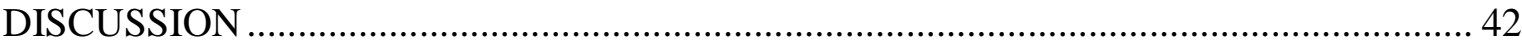

Effect of $u s 1$ gene mutation on DNA replication and gene expression in PRV ................ 42

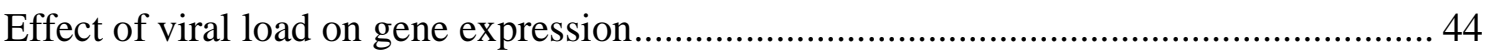

Recombinant viruses in electrophysiological measurements ........................................... 45

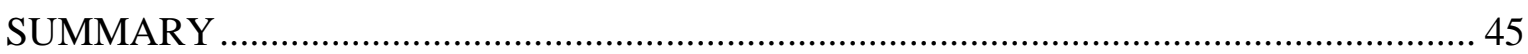

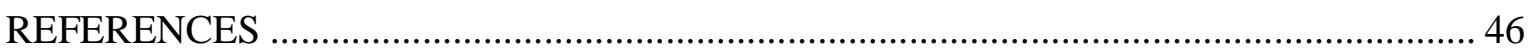

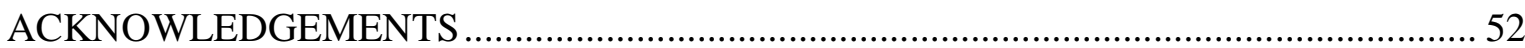




\section{LIST OF ABBREVIATIONS}

$\begin{array}{ll}\text { ASP } & \text { Putative Antisense promoter } \\ \text { AST } & \text { Antisense transcript } \\ \text { bp } & \text { Base pair } \\ \text { Cdc } & \text { Cell division cycle } \\ \text { Cdk } & \text { Cyclin dependent kinase } \\ \text { CFP } & \text { Cyan fluorescent protein } \\ \text { CMV } & \text { Cytomegalovirus } \\ \text { CNS } & \text { Central nervous system } \\ \text { Ct } & \text { Cycle threshold } \\ \text { DDT } & \text { Dichlorodiphenyltrichloroethane } \\ \text { DMEM } & \text { Dulbecco's Modified Eagle Medium } \\ \text { DNA } & \text { Deoxyribonucleic acid } \\ \text { E } & \text { Early } \\ \text { E } & \text { Eluorescence resonance energy transfer } \\ \text { E/L } & \text { Elycoprotein B, C, D, E, H, I, K or L } \\ \text { EDTA } & \text { Early/late } \\ \text { EHV-1 } & \text { Ethylene diamine tetra-acetic acid } \\ \text { ep0 } & \text { Equine herpesvirus-1 } \\ \text { FP } & \text { or L }\end{array}$


GFP

HHV

$\operatorname{HSV}(-1,-2)$

ICP

IE

IGL

IR

IRS

$\mathrm{KO}$

L

LAT

mRNA

memGFP

MOI

OPN

ORF

PBS

PCR

pi

PK-15

PRV

$\mathrm{R}$

$\mathrm{R}_{\mathrm{A}}$

$\mathrm{R}_{\Delta}$
Green fluorescent protein

Human herpesvirus

Herpes simplex virus (type-1 and type-2)

Infected cell protein

Immediate early

Inter-geniculate leaflet

Inverted repeat

Internal repeat sequence

Knock-out

Late

Latency associated transcript

messenger ribonucleid acid

Membrane-targeted green fluorescent protein

Multiplicity of infection

olivarypretectal nucleus

Open reading frame

Phosphate buffered saline

Polymerase chain reaction

Postinfection

Porcine kidney 15

Pseudorabies virus

Relative expression ratio

Rates of change

Net increase of the relative expression ratios between two time points 
VIII

$r$

ref

RING

RNAP II

RT

PCR

SCN

SDS

$\mathrm{Tm}$

TRS

UL

US

VHS

VZV

wt

YFP
Pearson correlation coefficient

reference

Really Interesting New Gene

RNA-polymerase type II

Reverse transcription

Polymerase Chain Reaction

Suprachiasmatic nucleus

Sodium dodecyl sulfate

Melting temperature

Terminal repeat sequence

Unique long

Unique short

Virion host shutoff

Varicella zoster virus

Wild-type

Yellow fluorescent protein 


\section{INTRODUCTION}

\section{Pseudorabies virus}

Pseudorabies virus(suid herpesvirus-1) is a member of Varicellovirus genus, Alphaherpesvirinea subfamily and Herpesviridae family. Its closest relatives are: Bovine herpesviruses, Caprineherpesvirus 1 (goat herpesvirus), Cercopithecineherpesvirus 9 (Simian varicella virus), Equidherpesviruses, Human herpesvirus 3 (Varicella-zoster virus, VZV). Another human pathogenic relatives are Herpes Simplex virus type 1 and 2 (HSV-1 and 2). Members of Herpesviridae are pathogenic; therefore it is very important to know their structure and infecting propertiesAladarAujeszky, a Hungarian veterinarian discovered a disease caused by pseudorabies, and differentiated it from the real rabies infection in 1902 [1]. The virus is pathogenic to virtually most mammalsexcept from humans and tailless apes [2]. It causes mild infection in adult swine, but usually fatal to young animals and nonporcine mammals, such as cattle, sheep, goats, dogs, cats and other [3]. The airborne infection leads to upper respiratory symptoms in adults and severe neurological symptoms, meningitis and encephalitis in young animals[1]. Due to the viral characteristics, like nonhuman pathogenicity, easy propagation, it is a very popular model organism of herpesviruses.

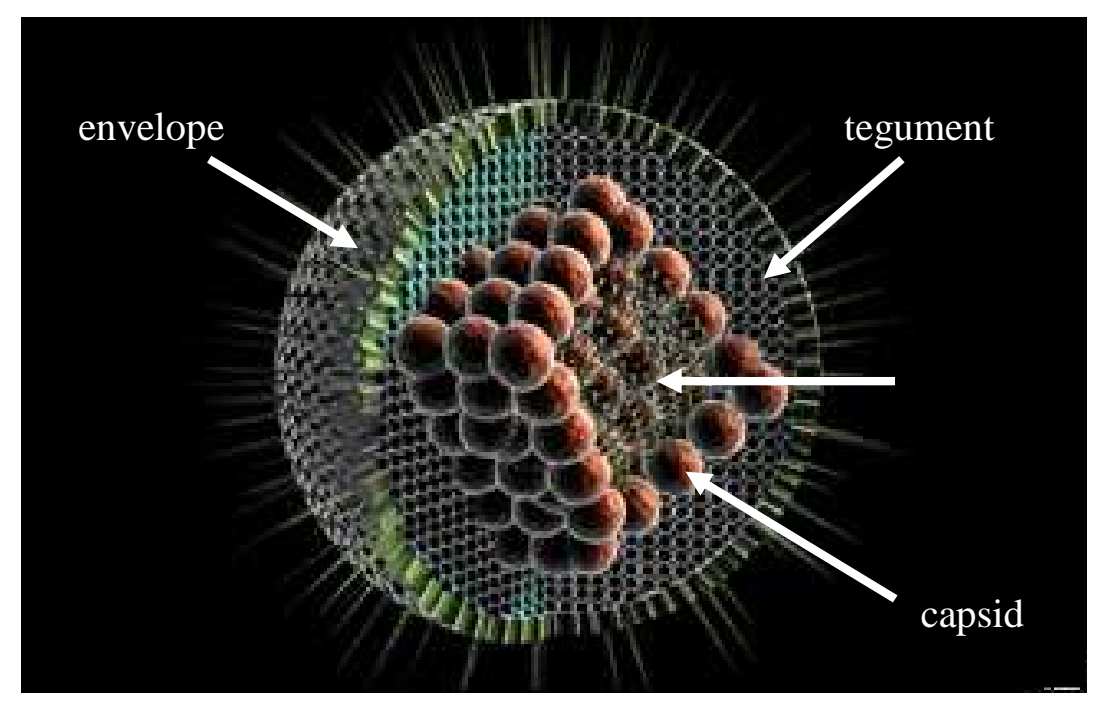

Figure 1.Schematic structure of a herpes virusVirion is built of four components: innermost DNA surrounded by 


\section{Structure}

Herpesviruses all share a common structure. The maturevirion consists of four components: the innermost part is the viral genome, which is covered by the icosahedral capsid (Figure 1.). The capsid is embedded in the

proteins. Finally, the tegument is surrounded by tegument made of envelope, a bilayer lipid membrane containing several glycoprotein spikes. The viral genome is 143,000 basepair (bp) long, lineardouble-stranded DNA molecule, and has 70 genes. The capsid of $125 \mathrm{~nm}$ diameter is made of 162 capsomers[2]. The tegument contains both viral proteins and mRNAs.

\section{Life cycle}

Pseudorabies virus (PRV) has latent and lytic forms. However, mature virion has to enter the cell first. For this, PRV uses several mechanisms and proteins, detailed in the followings. Upon entry to the cell, PRV uses its glycoprotein C proteins to anchor with heparin sulfate proteoglycans in the extracellular matrix. Next, PRV binds to specific cellular receptors via glycoprotein $\mathrm{D}(\mathrm{gD})$ to stabilize the virion-cell interaction. These specific cellular receptors are called herpesvirus entry mediators. Most conserved and effective is HveC (nectin 1), highly conserved among mammals. It can mediate the entry of HSV-1, HSV-2, PRV, and BHV-1. After entering the cell, the virion continues towards the nucleus. With the help of glycoprotein $\mathrm{B}, \mathrm{H}$, and $\mathrm{L}(\mathrm{gB}, \mathrm{gH}$, and $\mathrm{gL})$ the viral envelope fuses with the cellular plasma membrane and the tegument and viral capsid penetrate into the cell cytoplasm. Cell fusion can be induced in the absence of $\mathrm{gD}$, in transfected cells expressing PRV $\mathrm{gB}, \mathrm{gH}$ and $\mathrm{gL}$. Therefore $\mathrm{gD}$ is required for PRV penetration but not for cell-to-cell spread [4].During the following step the capsid attaches to dynein, a microtubule-associated motor protein, and travels from the cell periphery to the nuclear pore. After the capsid docks at the nuclear pore, the genomic DNA is released into the nucleus from the morphologically intact capsid. Then the host transcription factors and RNA polymerase II recognize the appropriate genes, and the transcription and translation begins. Details of this process are discussed below. During 
infection, from lytic phase virus goes to latency phase, and resides in the nucleus of host cell, in case of PRV in trigeminal ganglia of pigs [5]. In response to any disturbing effect, virus can reactivate and return to lytic phase. Right after the DNA enters to the nucleus, linear DNA becomes circular. Genome circularization probably occurs by blunt end ligation of the free ends and no viral protein is needed for the process. The circular genome serves as a template for DNA synthesis. First the synthesis occurs via theta replication, but it quickly switches to rolling-circle mechanism. The products are long concatemeric genomes that serve as the substrate for genome encapsidation[6].

Capsid assembly occurs in the nucleus with mature capsid constituents and two scaffolding proteins. These proteins are not present in the mature virion[7]. Regarding the content of capsids, we can differentiate three types: A-capsid (no protein or DNA inside, abortive form, failed to package DNA), B-capsid (filled with the cleaved form of one of the scaffold protein) and C-capsid (contains densely coiled viral DNA) [8]. DNA encapsidation requires two events; first, the replicated concatemeric DNA has to be cleaved into monomeric units, then these linear monomers has to be packed into capsids [9]. Highly conserved domains are responsible for directing the site-specific DNA cleavage and packaging, in which at least six PRV genes play role [10]. After the capsid is ready, with the DNA inside, they cross the nuclear envelope and participate in two envelopments before they are released from the cell. During the first envelopment the capsid buds into the perinuclear space through the inner nuclear membrane. These capsids called primary enveloped virions later exit from the perinuclear space, and the primary envelope fuses with the outer nuclear membrane resulting in deenvelopment of capsids. US3 protein is required for the entry of naked capsids into the cytoplasm. The next step is the addition of tegument followed by the secondary envelopment. Similar to matrix proteins, some of the outer layer proteins of tegument interact with the inner side of the envelope and with the inner tegument protein attached to the capsid, therefore joining these structures ready for secondary envelopment. Interaction between tegument and envelope proteins drive the secondary envelopment, which occurs on the cytoplasmic face of a specialized compartment derived from the Golgi network. Deletion of certain tegument proteins results in the accumulation of unenveloped cytoplasmic capsids [11]. Finally, the mature virion is brought to the cell surface within a sorting compartment derived from the envelopment compartment [2]. 


\section{Genome}

Pseudorabies virus genome has unique long $\left(\mathrm{U}_{\mathrm{L}}\right)$ and unique short $\left(\mathrm{U}_{\mathrm{S}}\right)$ region. The $\mathrm{U}_{\mathrm{S}}$ region is flanked by inverted repeat(IR) sequences (internal and terminal inverted repeat sequences (IRS and TRS)). Among the 70 genes, 40 are conserved in alpha-, beta- and gammaherpesvirinea families. These core genes are responsible for the basic function of virus, replication, structure, viral entry and egress from the cell, and found in the $\mathrm{U}_{\mathrm{L}}$ region of the genome.

\section{Genes,transcription}

The cascade-like transcription is also shared among Herpesviridea. Based on the temporal appearance of transcripts, the genes can be divided into three classes: immediate early (IE), early (E) and late (L) genes. IE genes are responsible for start of transcription and gene regulation, and do not require any viral protein or product for their transcription. E genesrequire viral transactivators, and their transcription is sensitive to protein translation inhibitors e.g. cycloheximide. Transcripts appear around 1 hour postinfection, and their level peaks around 3-4 hours after infection, while the proteins are synthesized most abundantly between 1 and 4 hour postinfection (pi). Early genes mainly encode proteins required for the nucleotide metabolism and DNA replication. Transcripts of late genes are present 2.5 hour postinfection, and the protein appears at the $3^{\text {rd }}$ hour of infection. L gene products are structural proteins, mainly for virion assembly and egress [2].

In Herpes Simplex, all the regulatory genes are the member of IE group (these infected cell proteins (ICP) are the ICP0, 4, 22, 27 and 47). In Pseudorabies, only the ICP4 homologue ie180gene is transcribed with immediate-early characteristic. The ie180 transcript synthesized within 40 minutes of the onset of infection, and the protein synthesis occurs till 2.5 hours postinfection[2]. Ie180 gene is present in two copies in the genome, located in the IRS and TRS repeats. The product of this gene is the major essential regulator of the transcription cascade of the virus[12]. The protein contains two domains, a DNA-binding and a transactivator domain, the strong acidic activation domain maps to the $\mathrm{N}$ terminus [13].Promoter of ie180 is recognized by host transcription factors and RNA polymerase II, 
and it drives the reporter gene in the absence of any viral protein or infection[14]. IE180 also can bind to its own promoter, therefore the observed negative autoregulation can be considered direct [15]. IE180protein is essential for growth in cell culture and required for efficient transcription of early viral genes [2]. The antisense pair of ie180 is called latencyassociated transcript (LAT), which is transcribed during latency, and cannot be detected in productively infected cultures $[16,17]$. There is a reverse regulatory mechanism between the ie180 and LAT, which enhance the reactivation from latency. IE180 represses the LAT promoter via interaction between IE180, LAT promoter and cellular protein[18].

Other regulatory genes are transcribed with early kinetics, such as ep0, ul54 and us 1 (ICP0, ICP27 and ICP22 homologues in HSV-1, respectively).

$E p 0$, such asie180, functions as a transactivator of the viral gene promoters.EpO is expressed with early kinetic, the protein can be detected within 2 hours after infection [19]. Recombinant EP0 activate transcription initiation from synthetic TATA-based promoters [20]. EP0 protein contains a RING (Really Interesting New Gene) finger domain, which is conserved between alphaherpesvirus ICP0 homologs. In HSV, ICP0 is responsible for gene expression, stimulation of lytic infection, enhancement of reactivation from quiescence, disruption of ND10 structures, induction of proteasome-dependent degradation of cellular proteins, and interaction with cyclin D3 [21]. HSV ICP0-deleted virus exhibits impaired growth in cell culture, its growth burst size are 10- to 100-fold lower than that of wild-type virus (wt)[22].EpO-negative PRV mutants can grow in cell culture, but the viral titers and plaque size are reduced $[23,24]$. Lack of $e p 0$ in PRV caused increased expression during the early stage of infection and alternating inhibitory and stimulatory effects on transcription in the late stage of infection [25]. Most of the epOgene overlaps with the oppositely transcribed antisense transcript (AST)[17].

UL54 is an important multifunctional protein which plays role in transactivation of viral and cellular genes, splicing and translation. Ul54null mutant virus exhibits a small-plaque phenotype in cell culture, and also highly attenuated in a mouse model of PRV infection. Ul54 null mutant-infected animals survive twice as long as animals infected with wild-type virus and this causes delayed accumulation of virus-specific antigens in skin, dorsal root ganglia, and spinal cord tissues. Changes of gene expression are different considering the different targets, e.g.gC and $\mathrm{gK}$ proteins accumulated lower levels than during wild-type 
infection, but level of $\mathrm{gB}, \mathrm{gE}$ and US9 products were lower in $u l 54$ null-mutant infected cell than in wild-type infected cells. DNA replication was also reduced in the mutant infected cells [26].

Us1(ICP22 in HSV) is also a regulatory gene, which is an odd-one-out, becausebased on previous experiments there is no consensus as to whether the PRV usl gene is expressed in IE, E or L kinetics[27-29]. Interestingly, us1, similar to iel80 is located in the IR region of the genome; therefore PRV has two copies of usl genes so as of iel 180 gene. In the literature, presence of us 1 null-mutant PRV virus is not known, therefore most of our knowledge about us 1 function derives from studies conducted with HSV ICP22-null mutant viruses. It has been shown in 1993, that ICP22 deleted mutant HSV was able to infect Vero cells productively but was severely restricted in human and rodent cells, and caused prolonged expression of some early gene products and delayed appearance of some late gene [30]. Ability of ICP22 mutant to cause death was also impaired in mice following intracerebral, intraperitoneal, or intravaginal inoculation. Furthermore, the mutant failed to produce lesions or other visible signs of infection after bilateral corneal infection of mice[31]. The equine herpesvirus 1 (EHV-1) homolog of pseudorabies virus us1 (called IR4)has two transcripts, a longer and shorter one [32]. The protein translated from the longer mRNA is more abundant in the virion. The same group showed that IR4 is localized predominantly in the nucleus and is dispersed uniformly throughout the nucleus [33]. In HSV, later studies revealed that ICP22 in necessary for changing RNA polymerase II (RNAP II) phosphorylation during infection. Briefly, RNAP II exists in two forms, IIa (unphosphorylated form, is recruited to the preinitiation complex [34]), and IIo (phosphorylated form, actively involved in RNA chain elongation [35]). These two forms alternate during transcription cycles[36]. Rice et al. discovered a third form designated IIi, which can be found during HSV infection, and migrates on SDS-PAGE gel at positions intermediate between IIa and IIo[37]. In further studies they have shown that ICP22 protein is required to induce this form and to maintain normal gene expression. While induction of IIi and depletion of IIa is deficient in cells infected with this mutant, IIo form of the RNAPII is not depleted. Based on these data they assumed the role of another protein, and they found that in absence of ull3gene both the induction of IIi form and the depletion of IIa form is present, therefore ICP22 and UL13 possibly act on the same pathway [38].HSV-1 ICP22 mutant exhibits defects in viral late 
gene expression.Furthermore, the antisense transcription is significantly reduced in the mutant-infected cell, but the viral DNA synthesis is normal [39]. However, ICP22 is not required for shutoff of host RNAPII transcription [40]. Leopardi et al. showed that ICP22 forms a complex with ICP4, RNAP II and nascent DNA in the late stage of infection in the cell nuclei, after the onset of DNA synthesis, and in the absence of UL13 and US3 this complex formation is not present. Products of these latter genes are responsible for the posttranslational phosphorylation of ICP22 protein [41].In 2000, another complex formation was observed, called small dense nuclear bodies, which appear earlier than the RNAPII complex and contains ICP22, UL3, and UL4[42]. ICP22 and UL13 mediate the phosphorylation of carboxyl terminal domain of RNAPII [43].

Furthermore, ICP22 and UL13 viral genes play role in disappearance of cyclins A and B, and decrease in cdc2 level, which are main coordinators of G2/M transition in uninfected cells [44]. ICP22 physically interacts with cdk9, a constitutively active cyclin-dependent kinase involved in transcriptional regulation. A protein complex containing ICP22 and cdk9 phosphorylates in vitro the carboxyl-terminal domain (CTD) of RNAPII in a viral US3 protein kinase-dependent fashion. Indeed, ICP22 and cdk9 form a complex with CTD of RNAPII, and UL13 is needed for this process [43]. Also, expression of cellular S-phase cyclins was altered in an ICP22-dependent manner specifically when S-phase Vero cells were infected. ICP22 is required for deregulation of S and G2/M cyclins during infection of S-phase cells [45]. Rice et al. has identified the sequences of ICP22 gene which are responsible for aberrant phosphorylation of RNA polymerase II. They showed that there is a region between 240 and 340 residues in the C-terminal half of ICP22, which is critical for the RNAPII modification. N-terminal half does not have any effect on this modification. However, mutations in both the $\mathrm{N}$ - and C-terminal halves result in similar defects in viral late gene expression and growth[46].Bowman et al. showed that ICP22 represses its own promoter, and this repressive activity is strong enough to inhibit the ICP0-mediated transactivation of viral promoters[47].

\section{Neuronal tracing}

Our knowledge about how the brain works, despite the excessive amount of effort taken by excellent researchers, is still incomplete. We know the macroscopic and microscopic 
structures; all the anatomical regions are well understood. We know how the neurons look like, with the dendrites and axons, covered by Schwann-cells forming a myelin sheet. Further it is well known what type of neurons can be found in what brain region, and what brain regions are connected to each other. It is also well known how the synapsis are built, how the nerve impulse go from the cell body to the axon and from the dendrites to the cell body. Furthermore, we know how the anterograde and retrograde transport occurs in the axons and dendrites. This knowledge comes from mainly microscopic and electrophysiological studies. On the other hand, very little is known about the exact function of these mechanisms and the connections between neurons, whether the connection is functional, from which region to which region goes the information, and whether a particular region has inhibitory or excitatory effect on the other region. To answer these questions, different tracing methods was discovered and developed in the last century. First tracers were dyes, which have a lot of disadvantages. Dyes usually does not cross synapses, even if they do, the efficiency is very low.Microtubular system is used by these dyes, which is another drawback besides being not self-perpetuating. Based on the direction of transport, tracers can be anterograde and retrograde tracers. The first retrograde tracer was the horseradish peroxidase, the axon can take up the HRP and transport it to the cell body [48]. Later several dyes appeared but none of them meets the requirement of an appropriate tracer for functional studies: transneuronal tracers should be self-replicating, able to cross synapsis, and only synapsis, cell-to-cell spread is not allowed, transneuronal transfer should occur only one direction, and the number of synaptic steps should be easily identifiable. Further, all neurons should be labeled during the tracing route for longer periods. Finally, change in neuronal metabolism is not required. For this purposes viral tracers are the suitable tools.

\section{Viruses}

The first evidence that neurotropic viruses provides suitable tools for defining polysynaptic circuits was published in the 1970s by Kristensson and colleagues [49]. Among viral tracers, two groups of virus has been gaining popularity in the last decades: alphaherpesviruses (Herpes simplex virus type-1 and Pseudorabies) and a rhabdovirus, rabies virus[50]. The two groups have different properties which make them suitable for different purposes. First, alpha-herpesviruses can infect all type of neurons that innervate peripheral 
sites (e.g. primary sensory neurons, motoneurons, sympathetic and parasympathetic neurons) [51], but they propagate more efficiently in sensory and autonomic pathways[52, 53]. Therefore, they are not just suitable, but the only useful transneuronal tracers for studying sensory and autonomic innervation [54]. In contrast, rabies virus propagates to central nervous system (CNS) exclusively from motoneurons, which makes this virus the ideal transneuronal tracing tool for studying motor innervation [50]. Among the disadvantages of alpha-herpesvirus is worth to mention that they induce rapid neuronal degeneration and inflammatory response [55]. Furthermore, they spread from cell to cell between synaptically not connected neurons, and depending on the type of the virus, it can create false positive results when studying connectivity [54]. Because of these drawbacks it is not recommended to use alpha-herpesviruses in higher doses and for longer time period [56]. Earlier, another problem was the bidirectional spreading, but today certain modified strains has the advantage of unidirectional transfer [50, 57].In contrast, rabies does not change neuronal metabolism, propagates exclusively between connected neurons [58], their spread is unidirectional (retrograde). We can conclude that choice of virus should be made based on the target anatomical structure.

\section{Fluorescent dyes}

Green fluorescent protein (GFP) was isolated from Aequoreavictoria[59], and in prokaryotic (Escherichia coli) or eukaryotic (Caenorhabditiselegans) cells.Exogen substrates are not required for the fluorescence [60]. GFP is a 238 amino-acid containing polypeptide, its excitation maximum is at $397 \mathrm{~nm}$, and emission maximum is at $509 \mathrm{~nm}[61]$. The chromophor region is in the middle of the molecule. Other important fluorescent protein is DsRed, which was found inDiscosomaspecies[62]. Its excitation maximum is at $563 \mathrm{~nm}$, emission maximum is at $582 \mathrm{~nm}$. These two proteins can be considered the basic fluorescent proteins. Yellow, blue and cyan color-emittingfluorescent proteins are derived from GFP, with changing the amino-acid sequence of the molecule. During our research we have used FörsterResonance Energy Transfer (FRET). This is a mechanism describing energy transfer between two chromophores. A donor chromophore, initially in its electronic excited state, may transfer energy to an acceptor chromophore through coupling. In order to transfer energy, the two molecule has to be in close proximity to each other $(<10 \mathrm{~nm})$. Two molecules 
are widely used for FRET: citrine (new yellow mutant of GFP) and cyan fluorescent protein (CFP). CFP can be excited by $436 \mathrm{~nm}$ wave-lengthlight and it emits $480 \mathrm{~nm}$ wavelength light, which is the excitation maximum of the citrine. If CFP and citrine got close to each other, citrine emits yellow light. Based on this phenomenon, a molecule was developed to detect $\mathrm{Ca} 2+$ signals with using FRET by Heim et al. [63]. They have constructed fluorescent indicators for $\mathrm{Ca} 2+$, which consist of tandem fusions of a cyan-emitting mutant of the GFP, a troponin $\mathrm{C}$ variant TN-L15, and an enhanced yellow-emitting GFP. Binding of Ca2+ makes TN-L15 go through conformation change, therefore the two fluorescent protein comes closer, and FRET occurs between the flanking GFPs (Figure 2).

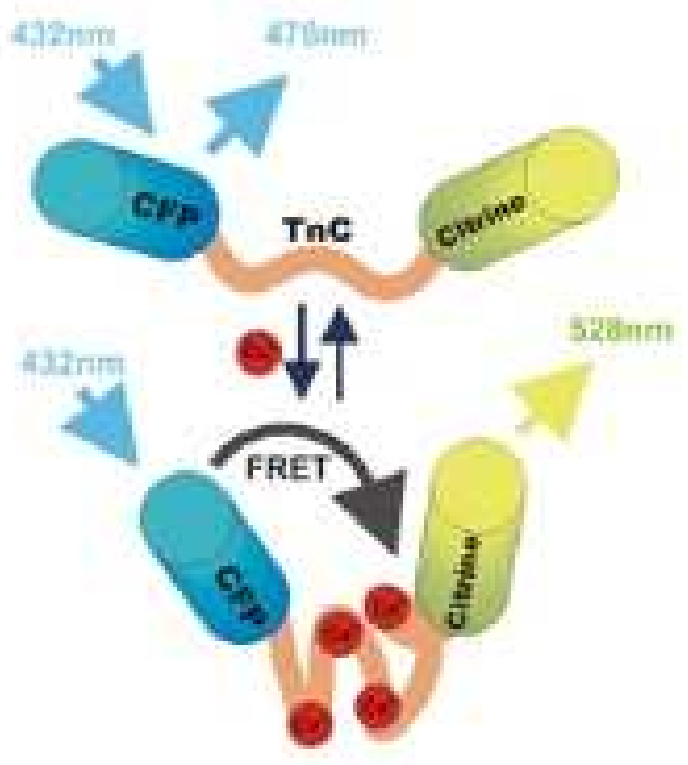

Figure 2. CFP-troponinCcitrinechimeraMoleculecontainst wofluorescentproteins, CFP and citrine, and a Ca2+ bindingtroponin C. Astroponin C bindscalcium, conformation of thechimerachanges, and FRET occurs.

\section{MATERIALS AND METHODS}

\section{Animals}

BALB/C and immunosuppressed CBA/J mouse strains were used for viral testing.

\section{Cells}


Porcine kidney 15 (PK-15) epithelial cells were propagated in monolayer culture. Cells were grown at $37^{\circ} \mathrm{C}$ with $5 \% \mathrm{CO}_{2}$, in filter capped $175 \mathrm{~cm}^{2}$ flasks (Orange Scientific) inDulbecco's modified Eagle medium (DMEM) (Sigma-Aldrich) containing 5\% fetal bovine serum (FBS) (Gibco) and $80 \mu \mathrm{g}$ gentamicin (Invitrogen ${ }^{\mathrm{TM}}$ ) per $\mathrm{ml}$.

\section{Virus strains}

Kaplan strain of Pseudorabies virus was used for generating mutant virus strains. These mutant virus strains were used for the above mentioned gene expression studies. For recombinant viruses containing fluorescent proteins also Kaplan strain of Pseudorabies virus was used, as well as for high and low titer studies.

\section{Construction of recombinant viruses}

Restriction enzymes, Klenow fragment, Ligase enzyme are the products of Fermentas.

\section{Us1 gene mutant virus strain}

Functional knock-out (KO) virus of $u s 1$ gene was generated as follows. BamHI-10 fragment of PRV was obtained with gel isolation, and then the fragment was subcloned to pRL525 plasmid, resulting pRL425-BamH10 plasmid.pBluescriptII KS (+) plasmid was modified with Ec1136II and NotI digestion, resulting a deletion between these restriction sites (pKS $\triangle \mathrm{EN}$ ). Further, pRL425-BamH10 was cut with BamHI, and the BamH10 fragment was cloned to the pKS $\triangle \mathrm{EN}$ plasmid, resulting pKSBamH10. This plasmid was digested with Ecl136II, resulting in a blunt end. Our previously modified, EcoRI-site flanked,CMV promoter-driven EGFP expression cassette (Clontech) was filled with Klenow and cloned to the Ecl136II site, resulting an insertion mutation in the usl gene (pUS1). This transfer plasmid was used for the generation of the knockout $(\mathrm{KO})$ virus. The ClaI-linearized plasmid was transfected with the purified wt viral DNA into PK-15 cells. Homologous recombination occurred, and the green fluorescent plaques were purified. Rescued viruses were generated by using pKSBamH10 as a transfer plasmid, which was cotransfected with the us 1 -KO virus to PK-15 cells. Revertant viruses were selected based on the non-fluorescent phenotype. Both mutant and rescued viruses were analysed with DNA sequencing. 


\section{Fluorescent protein-expressing virus strains}

Vesicle associated membrane protein (VAMP) GFP gene containing pBluescriptII KS (+) plasmid was used for generating VAMP-GFP expressing virus. This original plasmid contained an unnecessary EcoRI site, which was cut with EcoRI enzyme, then filled with Klenow enzyme followed by self-ligation. Further, XhoI digestion was performed, and after filling with Klenow, NotI linker was ligated to the XhoI site. Therefore the VAMP-GFP expression cassette was flanked by NotI site. This plasmid was cut by NotI, and the resulting expression cassette was cloned to the HCMV-P at the site of the previously removed lacZ gene. This resulted a CMV-promoter driven VAMP-GFP cassette, which was later inserted to the wild-type virus lacking $A S P, e p 0$ or $v h s$ genes. These viruseswere used as Timer virus with further genetic modifications.

For rainbow viruses, memRFP containingpBluescript KS plasmid was digested with EcoRI, and memRFP was isolated with gelelectrophoresis, and cut from the gel. The 525-B7 $\Delta \mathrm{gE}-\mathrm{gI}$ plasmid also was digested EcoRI, and memRFP was cloned to its EcoRI site. Cherry gene was used for generating Cherry containing 525-B7 $\Delta$ gE-gImemRFPplasmid. MemRFP gene was also cloned to ASP-Dup plasmid.

\section{Transfection, generation and isolation of recombinant viruses}

In order to verify the functioning of recombinant fluorescent protein-encoding expression cassettes, Lipofectamine ${ }^{\circledR} 2000$ Transfection Reagent (Invitrogen $^{\mathrm{TM}}$ ) was used for transfection to PK-15 cells following the manufacturer's recommendations. For generation of recombinant viruses, the linearized plasmids and wild-type virus were transfected simultaneously with transfection reagent to actively growing PK-15 cells. During transfection, homologue recombination occurred resulting recombinant viruses. Plaques formed by FP-carrying recombinant viruses were screened based on their fluorescence. Recombinant viruses were isolated by 6-15 cycles of plaque purifications using a fluorescence microscope (Olympus IX-71).

\section{DNA sequencing}


Mutant virus was subjected to DNA sequencing in Biotechnology Institute of Szeged (BAY-BIO),Bay Zoltán Nonprofit Ltd. for Applied Research with next generation sequencing. Sequences were analyzed by Chromas Lite 2.01 software (Technelysium Pty Ltd).

\section{Viral DNA preparation}

Purified wild-type viral DNA was used for generating recombinant viruses. Further, also purified recombinant viral DNA was used for infection. Viral DNA was isolated as follows: PK-15 cell monolayers were infected with the PRV at 10 multiplicity of infection (MOI), andincubated at $37^{\circ} \mathrm{C}$ until completecytopathic effect was observed. Next, culture medium was collected without disrupting the cells and clarified by centrifugation at 4,000 rpm for 10 min using a Sorvall GS-3 rotor. Subsequently, the virus in the supernatant fluids was sedimented on a $30 \%$ sucrose cushion by ultracentrifugation at 24,000 rpm for $1 \mathrm{~h}$ using a Sorvall AH-628 rotor. The sedimented virus was resuspended in sodium Tris-EDTA buffer. After this step, proteinase-K (100 $\mu \mathrm{g} / \mathrm{ml}$ final concentration) and sodium dodecyl sulfate (SDS; $0.5 \%$ final concentration) was added, and the lysate was incubated at $37^{\circ} \mathrm{C}$ for $1 \mathrm{~h}$. Finally, it was purified by phenol-chloroform extraction and dialysis.

\section{Viral infection}

For gene expression analysis ofus 1 mutant virus, rapidly growing PK-15 cells (approximately $1 \times 10^{7}$ ) were infected with high MOI (10 plaque-forming unit(pfu)/cell) of either $u s 1-K O$ or wt strain of PRV at -1 hour time point. After one hour, virus containing $0 \%$ DMEM was removed, and 5\% FBS containing DMEM was added to the cells. Cells were harvested at $0.5,1,2$, and 4, 6, 8, 12, 18 and 24 hours later. In each time point at least 3 flasks of infected cells were used. The harvested cells were centrifuged with $600 \mathrm{rpm}$ in swing-out rotor centrifuge, and then resuspended in $1 \mathrm{ml}$ phosphate-buffered saline (PBS). $100 \mu 1$ of the cell suspension was separated for DNA measurements; $900 \mu 1$ was used for gene expression studies. Cells were further centrifuged and then kept on $-80^{\circ} \mathrm{C}$ until RNA or DNA extraction. 
For low and high MOI experiments $5 \times 10^{5}$ and $5 \times 10^{7} \mathrm{pfu}$ viral particles $(0.1 \mathrm{pfu} / \mathrm{cell}$ and 10 pfu/cell), respectively, were applied for the infections. Therefore, in the high-MOI experiment practically all the cells were infected, while in the low-MOI experiment, approximately $10 \%$ of the cells were infected by the virus.

\section{RNA isolation}

Cells were processed with NucleoSpin RNA II Kit (Macherey-Nagel GmbH and Co.) according to the given protocol. Briefly, cells were lysed by incubation in a solution containing chaotropic ions. This buffer immediately inactivates RNases, and creates appropriate conditions for RNA for binding to the silica membrane. Contaminating DNA was digested by rDNase via applying directly to the silica membrane. Salts, metabolites and macromolecular cellular components were removed during the two washing steps with two different buffers. Finally, RNA was eluted under low ionic strength conditions with $60 \mu 1 R N a s e-f r e e$ water. Further, Turbo ${ }^{\mathrm{TM}} \mathrm{DNase}$ (Ambion Inc.) treatment was applied to remove the remaining, low amount of DNA ( $2 \mathrm{U}$ enzyme was added to the total RNA, and incubated at $37^{\circ} \mathrm{C}$ for 30 minutes, then the DNase was inactivated by heating at $75^{\circ} \mathrm{C}$ for 30 minutes, with adding EDTA to a final concentration of $15 \mathrm{mM}$, in order to prevent RNA degradation). The RNA concentration was measured three times in case of each sample with BioPhotometer Plus spectrophotometer (Eppendorf). RNA samples were stored at $-80^{\circ} \mathrm{C}$ until further use.

\section{Reverse transcription}

Reverse transcription was performed based on SuperScript ${ }^{\mathrm{TM}}$ III Reverse Transcriptase (Invitrogen ${ }^{\mathrm{TM}}$ ) protocol. Reactions were performed in $5 \mu \mathrm{l}$ final volume. During the first step, 70ng of the previously recovered RNA was mixed with $0.25 \mu 1$ (2pmol final concentration) of gene- and strand specific primer,0.25 $\mu 110 \mathrm{mMdNTP}$, and $0.5 \mu 1$ UltraPure $^{\mathrm{TM}}$ DNase/RNase-Free Distilled Water (Gibco). This mix was heated at $65^{\circ} \mathrm{C}$ for 5 minutes then incubated on ice. In the second step, $1 \mu 15 \mathrm{x}$ first strand buffer, $0.25 \mu 1100 \mathrm{mM}$ DDT, and $0.25 \mu 1$ SuperScript ${ }^{\mathrm{TM}}$ III Reverse Transcriptase enzyme was added to the mixture on ice. This mixture was incubated at $55^{\circ} \mathrm{C}$ for 60 minutes, and then the reaction was stopped by 
heating at $70^{\circ} \mathrm{C}$ for 15 minutes.As a control, the reaction was performed without reverse transcriptase to test the potential viral DNA contamination.

\section{Primers for reverse transcription (RT) and polymerase chain reaction (PCR)}

Primers pairs were used as described previously [29]. Briefly, primer pairs was designed using the Primer Express program (Applied Biosystems) and the FastPCR Professional (Primer Digital Ltd.) oligonucleotide design software according to the given guidelines. All primers were designed to the 3'-end regions of the open reading frames (ORFs) for each gene. Specificity of the primers was verified by BLAST searches of the GenBank database (National Center for Biotechnology Information (NCBI) website (http://www.ncbi.nlm.nih.gov/BLAST/). Oligonucleotide primers were purchased from Bio Basic Inc. (Mississauga, Ontario, Canada).

\section{Real-time PCR}

Real-time PCR experiments were performed by using the Rotor-Gene 6000 thermal cycler (Corbett Life Science). Tenfold dilution of cDNA from the previous step was used for the real-time PCR. For the reaction, $10 \mu 1$ of diluted cDNA, $7 \mu 1$ of ABsolute QPCR SYBR Green Mix, $1.5 \mu \mathrm{l}$ forward, and $1.5 \mu \mathrm{l}$ reverse primer was mixed resulting in $20 \mu 1$ final volume. The mix was incubated at $95^{\circ} \mathrm{C}$ for 15 minutes, followed by 30 cycles denaturation $\left(94^{\circ} \mathrm{C}, 25 \mathrm{sec}\right)$, annealing $\left(60^{\circ} \mathrm{C}, 25 \mathrm{sec}\right)$ and extension $\left(72^{\circ} \mathrm{C}, 6 \mathrm{sec}\right)$. Melting curve analysis was used at the end of the PCR to ensure the specificity of the primers and absence of primer dimers (from $55^{\circ} \mathrm{C}$ to $95^{\circ} \mathrm{C}$ ). In case of those primers which produced primer dimers, an additional extension and detection step was included for $2 \mathrm{~s}$ at a temperature just below the $\mathrm{Tm}$ of the specific product and substantially above the melting temperature $(\mathrm{Tm})$ of the primer dimers. Controls were as follows: loading control (28S ribosomal (r)RNA (reference gene) was amplified in each run), no template control (amplification of $\mathrm{H}_{2} \mathrm{O}$ ), negative mockinfected control (cDNA derived from the reverse-transcribed RNAs of non-infected cells).

\section{DNA extraction}


$100 \mu 1$ of the cell suspension per flask was separated after harvesting, and centrifuged as mentioned before. Cells were frozen at $-80^{\circ} \mathrm{C}$. The frozen cells were lysed in the following lysis buffer: 50 mMTris-HCl, pH 8.0, $10 \mathrm{mM}$ EDTA, 1\% SDS, $20 \mathrm{mMNaCl}$. $500 \mu \mathrm{l}$ of lysisbuffer was added to the cells with proteinase K $(50 \mu \mathrm{g} / \mathrm{ml}$ final concentration, SigmaAldrich). The suspension was incubated at $55^{\circ} \mathrm{C}$ for 6 hours. After, $500 \mu \mathrm{l}$ ofPhenol:Chloroform:Isoamyl Alcohol 25:24:1 (Sigma-Aldrich) extraction solution was added, and the mixture was vortexed to remove the proteins. The upper, aqueous solution was transferred to a new tube, and one tenth of $3.25 \mathrm{M} \mathrm{Na}$-acetate and 2.5 volume of $100 \%$ ethanol were added, and incubated on $-20^{\circ} \mathrm{C}$ overnight. Then high speed centrifugation followed by a washing step with $70 \%$ ethanol was applied, the DNA was dried and solved in $100 \mu \mathrm{l}$ distilled water.

\section{Real-time PCR for DNA measurement}

$0.7 \mu \mathrm{g}$ DNA was used for each PCR reaction in a final volume of $20 \mu 1$. The reagents and the PCR running conditions were the same as mentioned below.

\section{Statistics}

The following mathematical model was used for calculating the relative expression ratio:

$\mathrm{R}$ means relative expression ratio or relative copy number, $\mathrm{E}$ stands for the efficiency of amplification in a reaction cycle; $\mathrm{Ct}$ is the threshold cycle value; sample refers to any particular gene at a given time point; and ref is the 28S rRNA, which was used as a reference gene.The equation was modified from Soong's formula [64], using the average maximum value of $\mathrm{E}^{\mathrm{Ct}}$ for each gene as the control instead of individual values. The Comparative Quantitation module of the Rotor-Gene 6000 software (Version 1.7.28, Corbett Research) automatically calculates the real-time PCR efficiency sample-by-sample. Thresholds were set automatically by the software. Data were analyzed by the MicrosoftExcel program, average, 
standard error, and standard deviance functions of the software were used. $R_{A}, R_{\Delta}$ and $R_{r}$ values were used to measure the gene expression changes, and the effect of mutation.

$\mathrm{R}_{\mathrm{A}}$ stands for the rate of change in between two consecutive time points: ${ }^{R_{A}}={ }^{R_{(t+1)}} / R_{t} \cdot \mathrm{R}_{\Delta}$ means the net change in $\mathrm{R}$ between two time points, and was calculated via the following formula: ${ }^{R_{3}}={ }^{R_{t+1}} / R_{t}$. The effect of mutation of $u s 1$ gene on the gene expression was calculated by using the $R_{r}$ values, a ratio between the $R$ values of usl-KO and wtPRVs $\left(R_{r}={ }^{R_{u z 1-K o}} / R_{w t}\right)$, where $\mathrm{R}_{u s l-\mathrm{KO}}$ and $\mathrm{R}_{\mathrm{wt}}$ represent the $\mathrm{R}$ value of a particular gene at a given time point in usl-knockout and wild-type genetic background, respectively. A high $\mathrm{R}_{\mathrm{r}}$ value indicates an excessive inhibitory effect of the US1 protein on the transcript level of a particular gene in the wild-type virus. Furthermore, we have calculated the average $\mathrm{R}_{\mathrm{r}}$ for the $\mathrm{E}, \mathrm{E} / \mathrm{L}$ and $\mathrm{L}$ genes for every time points. The same method was used for calculating DNA measurements.For the experiment on viral load, we have used a correction factor of 10 for the calculation of $\mathrm{R}$ values for low-MOI infection. With this calculation technique, approximately the same numbers of infected cells, and hence the relative amounts of transcripts in an average infected cell, were compared in the low- and high MOI experiments. Furthermore, a tenfold division was used for normalization of $\mathrm{R}$ values to the copy number of DNA in this experiment. We have applied two ways of comparison of different genes in different time points. The one that I have already shown with calculation the $\mathrm{R}$ values, and we used another one, during which we normalized the $\mathrm{R}$ values to the relative copy number of DNA in each time point. This approach resulted in normalized $\mathrm{R}$ values ( $\mathrm{nR}$ values), and with using $\mathrm{nR}$ values we eliminated the distorting effect of changes in DNA copy number, so we could have focused on the mere gene expression. In other words, with the normalization we could determine the expression of a particular gene from one double-stranded DNA at a given time point.

Pearson's correlation was used for the analysis of the relationship between low- and highMOI and wild-type and mutant virus infections. This correlation allows to measure the linear relationship between two variables, $\mathrm{X}$ and $\mathrm{Y}$. Pearson's correlation coefficient (r) was calculated as follows:

$r=\frac{\sum_{i=1}^{n_{1}}\left(X_{i}-\bar{X}\right)\left(Y_{i}-\bar{Y}\right)}{(n-1) S_{x} S_{y}}$ 
where $\mathrm{X}$ and $\mathrm{Y}$ are the two variables, which are the $\mathrm{R}_{\Delta}$ values of two different genes in the same time interval (i). $\bar{X}_{\text {and }} \bar{Y}$ are the average values, $\mathrm{n}$ is the sample number, and $S_{x}$ and $S_{y}$ are the standard deviances (errors) for $\mathrm{X}$ and $\mathrm{Y}$.The coefficient ranges from -1 to +1 , and measures the degree of association between $\mathrm{X}$ and $\mathrm{Y}$. If $\mathrm{X}$ and $\mathrm{Y}$ are independent, Pearson's correlation coefficient is 0 . A positive $\mathrm{r}$ value for the correlation implies a positive association (high values of $\mathrm{X}$ tend to be associated with high values of $\mathrm{Y}$, and low values of $\mathrm{X}$ tend to be associated with low values of $\mathrm{Y}$ ). A negative value for the correlation means an inverse association (high values of $\mathrm{X}$ tend to be associated with small values of $\mathrm{Y}$, and vice versa).

\section{RESULTS}

\section{Us 1gene mutation exerts significant effect on gene expression and DNA replication}

In my main work I studied the effect of lack of us 1 gene on the global gene expression of PRV. In the literature, there was no pseudorabies virus present with mutation of usl gene. The first HSV-1 ICP22 mutant appeared in 1993 from Herman lab [30]. Null-mutant of VZV homologue of $u s 1$ is also known in the literature. Interestingly, in VZV the usl homologue ORF63 is expressed during latency, and it is required for latent infection [65]. It can be found in two copies of the genome, called ORF63/ORF70 gene pair (us1 gene also present in the genome in two copies). The gene product of ORF63/70 was necessary for VZV replication, but the presence of one copy of the ORF63/70 gene pair was sufficient for normal patterns of VZV replication and plaque formation in cell culture[66]. HSV-ICP22 null-mutant has similar features, as I described in the Introduction, but our knowledge about PRV usl is very limited. Furthermore, there were no gene expression studies about these gene products, neither in HSV nor in VZV or other alpha herpesvirus. These facts raised the question whether the uslgene has similar characteristics, what would be the features of theusl-KO mutant virus, and how would the mutation affect the transcription. In our group deletion of two other very important gene was studied with similar technique, ep0 and $v h s[25,67]$. In my thesis, I would like to show that $u s 1$ gene is very importantduring the life cycle of the virus, and changes the virus on a global scale. We studied DNA replication and gene expression in 
the wild-type and usl-KO mutant, and both were severely changed in the mutant. As I mentioned earlier, PRV has 70 genes, but only 32 were studied with real-time PCR. We have included those genes, which reside at the upstream position of the tandem gene clusters, and the reason for this being that these genes are not overlapped by other genes, and the amounts of these transcripts are therefore proportional to their protein products. This is in contrast with the downstream genes, which, if transcribed from the promoter of an upstream gene, are not translated, because they do not have cap sequences that are required for the recognition by the ribosomes. The reason for this choice was to exclude the distorting effect of the transcriptional read-through exerted by the upstream genes on the downstreamgenes. Furthermore, it was important to represent all the kinetic classes of PRV genes. Also, the genes selected for analysis playimportant roles in the regulation of the overall gene expression of the virus, including ie180, ep0 (andtheir antisense transcripts, the LAT and the AST, respectively), virion host shut-off ( $v h s)$, and $u l 54$ genes.

\section{DNA replication}

First, I would like to show my findings about the DNA expression. In the wild-type virus, amount of DNA was low during the first two hours, indeed, at the $30 \mathrm{~min}$ time point the amount of viral DNA was slightly higher than at 1 and at 2 hour pi (Figure 3). It is possible that the cellular DNases digest some portion of the infecting viral DNA molecules. After, the level of DNA began to raise at 4 hour, stayed the same level till 6 hour, and reached the highest level at 12 hour, then decreased (R values were the following: 0.5h: 0,080; $1 \mathrm{~h}$ : 0,019;

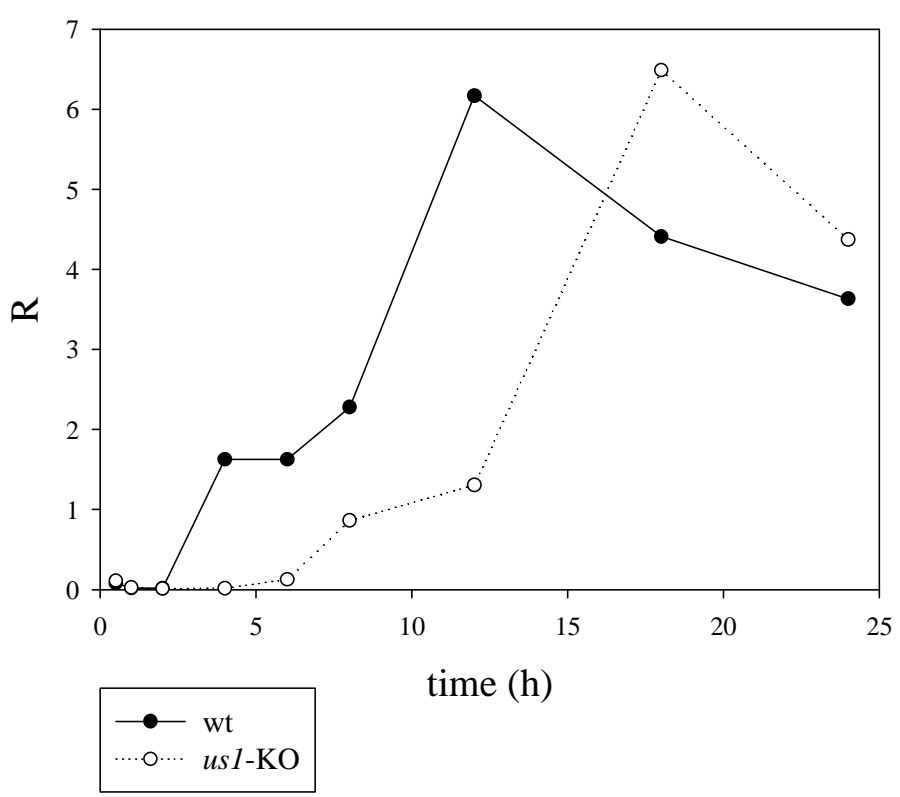

Figure 3. $R$ values of viral DNAOnset of DNA replication was delayed by 4 hours in us $1-K O$ mutant compared to wt virus 
2h: 0,017; 4h: 1,627; 6h: 1,625; 8h: 2,278; 12h: 6,169; 18h: 4,411; 24h: 3,634). Therefore we can state that the DNA replication started between the 2 and 4 hour time point. The plateau level might be explained with the switch from the theta-type replication to the rolling circle replication. Decrease of DNA from 12 hours possibly occurred because the mature virions egress from the infected cells around this time, therefore the viral DNA content of the cells decreases. We also measured the viral DNA levels in the us1-KO virus. Levels showed the same pattern as in the wild-type virus, but significant delay was observed in the onset of DNA synthesis (R values: 0.5h: 0,111; 1h: 0,027; 2h: 0,014; 4h: 0,017; 6h: 0,128; 8h: 0,865; 12h: 1,306; 18h: 6,487; 24h: 4,373). While in the wild-type virus the onset of DNA replication occurred between 2 and 4 hours, the DNA level started raising in between 4 and 6 hours. If we study it a bit more, this elevation was not steep, the increase was much more considerable between 6 and 8 hours. Therefore the delay was about 4 hour, which makes this difference very significant in the two virus. In the later stage of the infection, the pattern of DNA levels of $u s 1-\mathrm{KO}$ became very similar to the wild-type virus. Both virus reached the peak around the same $\mathrm{R}$ value, but highest $\mathrm{R}$ value was at 12 hours in wild-type virus, and at 18 hours at us1-KO. After the peak, DNA level declined in both virus also to the same level. Pearson correlation coefficient was 0.63 , which means that the DNA replication of the two virus is similar.Based on these findings we suggest that mutation of us 1 gene does not alter the mechanism of DNA replication, but the gene may benecessary for the initiation of DNA replication.

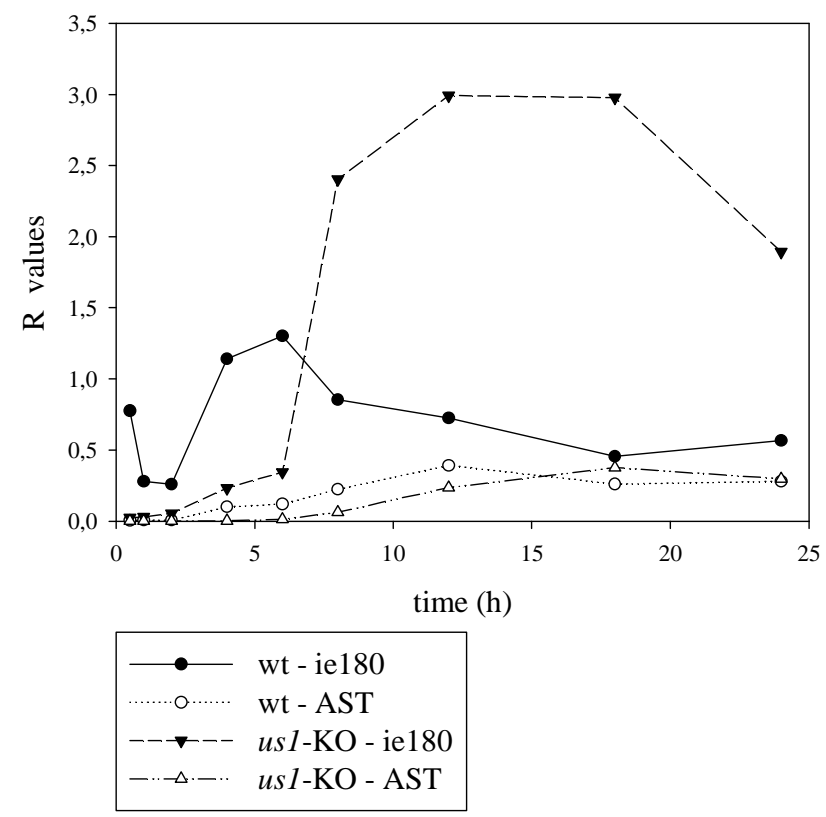

\section{Gene expression}

Regarding the gene expression, us 1 mutation has different effect on different kinetic classes of the virus. As I have

Figure 4. $R$ values of ie180 and its antisense pair, AST in wt and us1-KO mutantDelay in transcription and much higher peak can be observed in us1-KO virus 
mentioned in the Methods, we have evaluated the gene expression with using $\mathrm{R}$ values and $n R$ values. With using $R_{\Delta}$ we could determine the net change, and using $R_{A}$ we could tell the rate of changes during infection. After calculating the $n R$ values, we have applied the $n R_{\Delta}$ and $\mathrm{nR}_{\mathrm{A}}$ values for determining the gene expression per one copy of DNA.

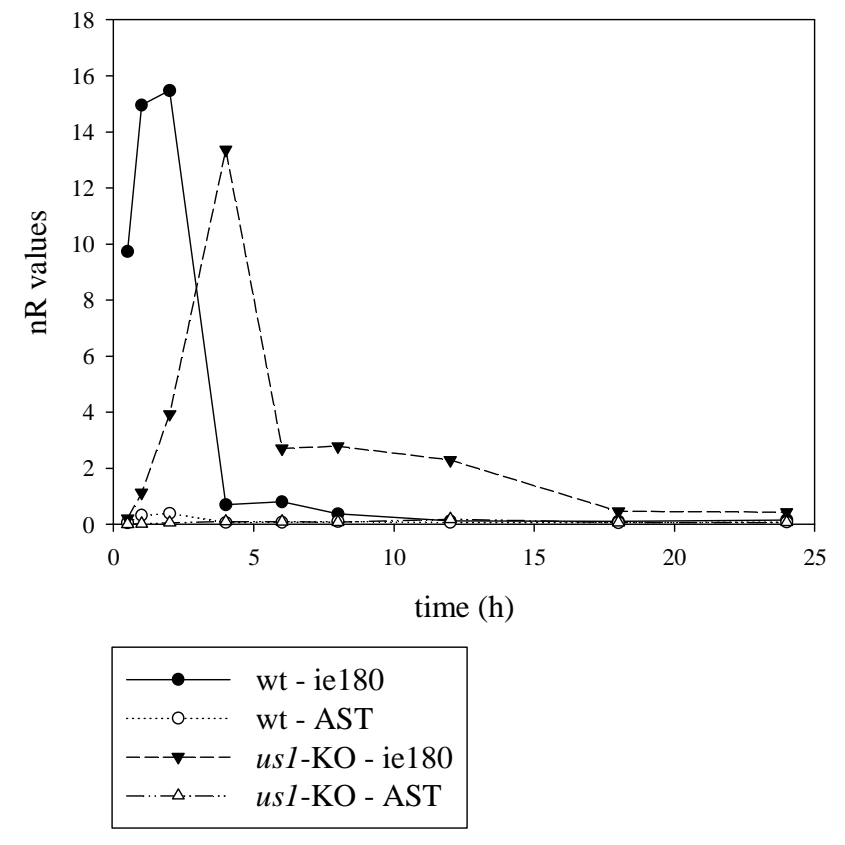

Figure 5.nR values of ie180 and its antisense pair, AST in wt and us1-KO mutantie180 transcription was 2 hour late in us1-KO compared to wt

\section{Effect on ie180}

Further, I would like to show the effect of usl mutation to each kinetic classes, starting withthe single intermediate-early gene ie180, later I am going to discuss the early, early/late and late genes. Figure 4 shows the difference regarding the expression of ie180 in wt and usl-KO mutant. There is an approximately 4-hour delay in increase of ie180 mRNA level in the $u s 1-\mathrm{KO}$, and its peak is two times higher than in the wt virus. Also the peak is at 12 hours, while in the wt it is at 6 hours which means a 6hour delay.In case of AST, antisense pair of ie180, the differenceis not that obvious,

overall levels of AST was higher in wt till 12 hour. At 18 hour levels of AST in us1-KO became higher and remained high till 24 hours. nR values are presented on Figure 5. nR values shows the transcriptional activity without the "disturbing" effect in changes of DNA levels. The delay is 2 hours considering the peak of transcripts of ie180. Later, levels of mRNA decrease rapidly and stay low during the infection. This delay can be explained by the fact that US1 protein is found in the tegument[68], and it is probably used from very early stage of infection. It is worth to mention that in PRV usl is expressed with late kinetics, 
while its HSV-1 homologue is expressed with immediate-early kinetic. Besides, ICP22 was undetectable in HSV-1 virions[69].

Effect on early genes

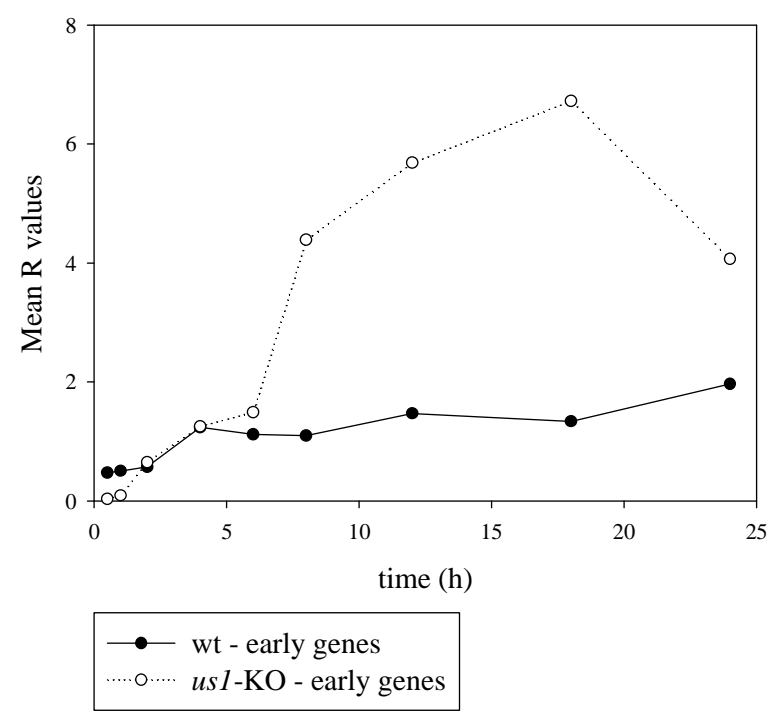

Figure 6. Average of $R$ values of early genes in wt and us1-KOus1-KO peaks 5 times more than wt virus

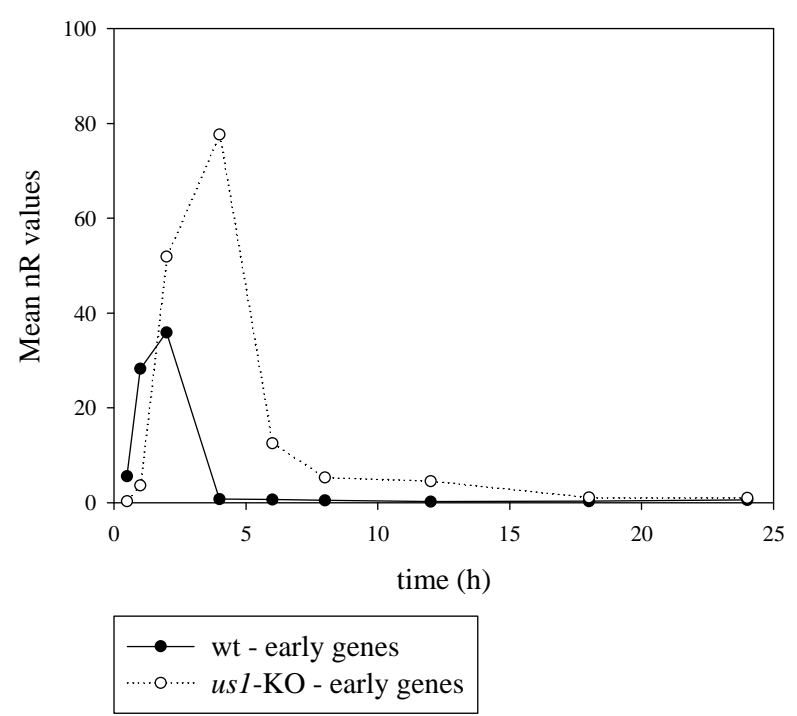

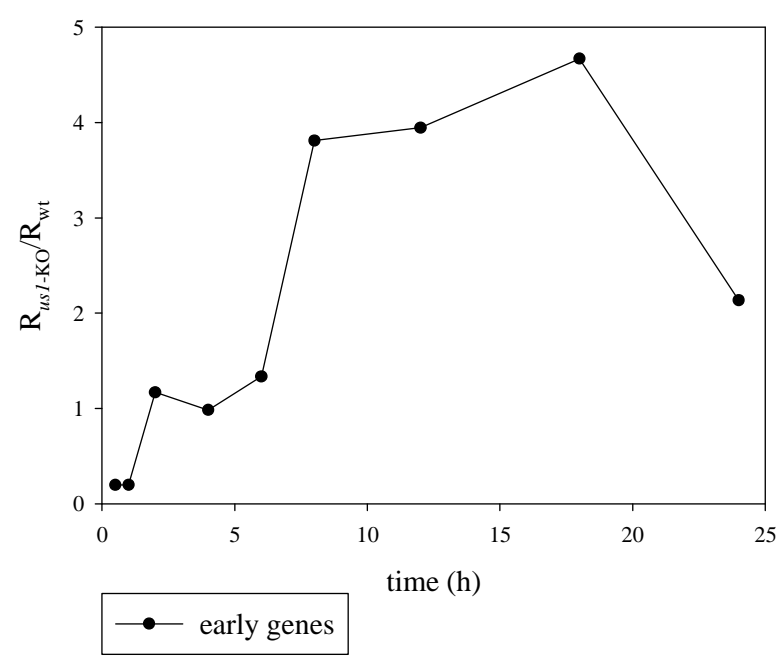

Figure 7. Ratio of average of $R$ values of early genes Ratio is more than one except from 3 time points: 0.5, 1 and 2 hour

Further, I would like to show the effect of usl gene mutation to each kinetic classes, then I highlight those genes, which were most affected by the mutation.Us1 mutation had the most impressive effect on the early genes.Figure 6 shows the mean $\mathrm{R}$ values of

Figure 8. Average of $n R$ values of early genes in wt and us1-KOPeak ofus1-KO is two times more than wt virus 
early genes in wtand in $u s 1-\mathrm{KO}$ virus. Average $\mathrm{R}$ values are four times higher at 8 hours, and almost five times higher at 18 hours of infection in wt virus (Figure 7). It means that us 1 had a very significant inhibiting effect on the early genes, especially in the later stages of infection, following the initiation of viral DNA synthesis. $\mathrm{nR}$ values also showed significant increase in gene expression of early genes. $\mathrm{nR}$ values of usl-KO mutant were almost 80 , while in wt the highest $\mathrm{R}$ values was below 40 (Figure 8). One-hour delay in onset of gene expression and two-hour delay in reaching the peak could have also been observed. These findings were consistent with the results of ie180, peaks werereached at the same time ( 2 and 4 hours, in wt and us1-KO, respectively).

\section{Effect on early/late genes}

Similar effects were observed in early/late genes. In usl-KO virus, transcription of E/L genes reached the peak at 12 hours, and $\mathrm{R}$ value was 3 times higher than in wt virus. This difference was a bit less than observed in case of early genes (Figure 9 and 10). nRvalues also showed similar pattern, but delay could have not been observed in the onset of increase

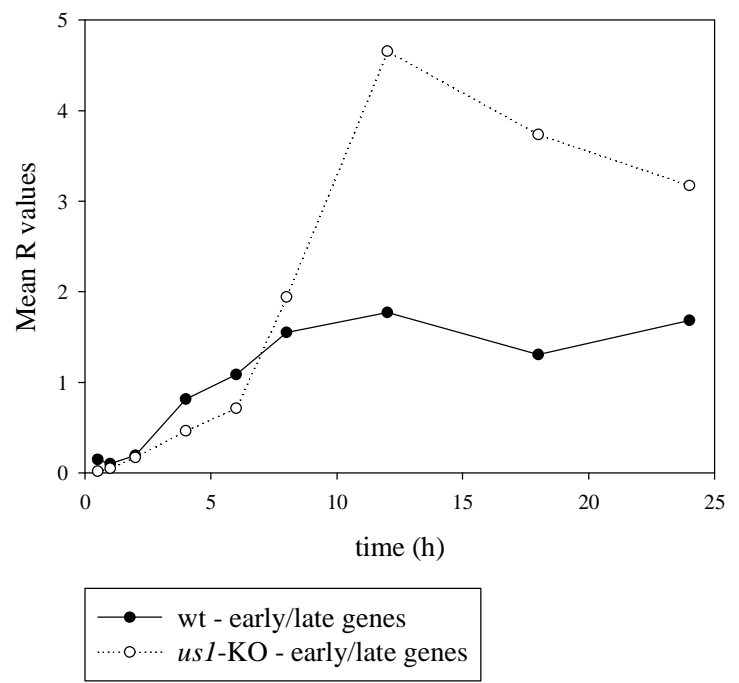

Figure9. Average of $R$ values of early/late genes in wt and us1-KOPeak ofus1-KO is three times higher than wt

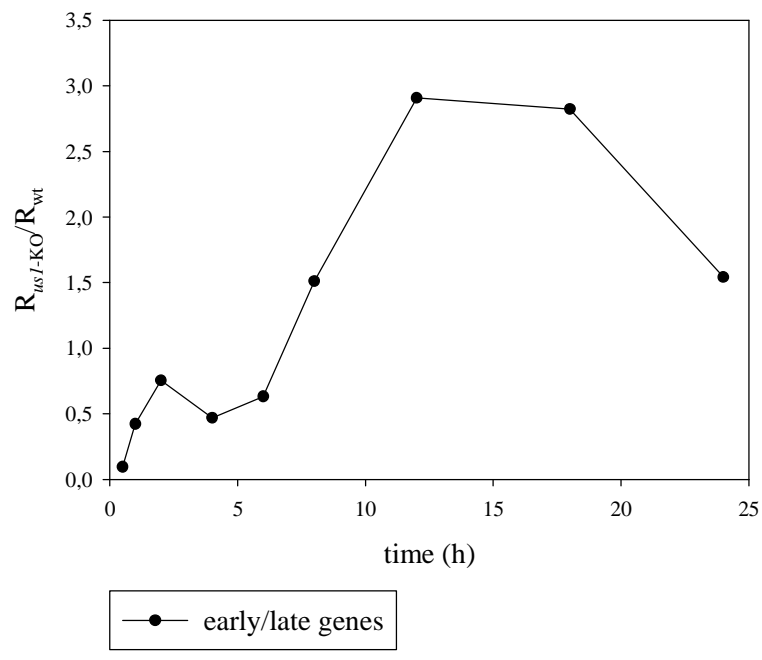

Figure 10. Ratio of average of $R$ values of early -late genes Ratio is more than one from 8 hour pi till 24 


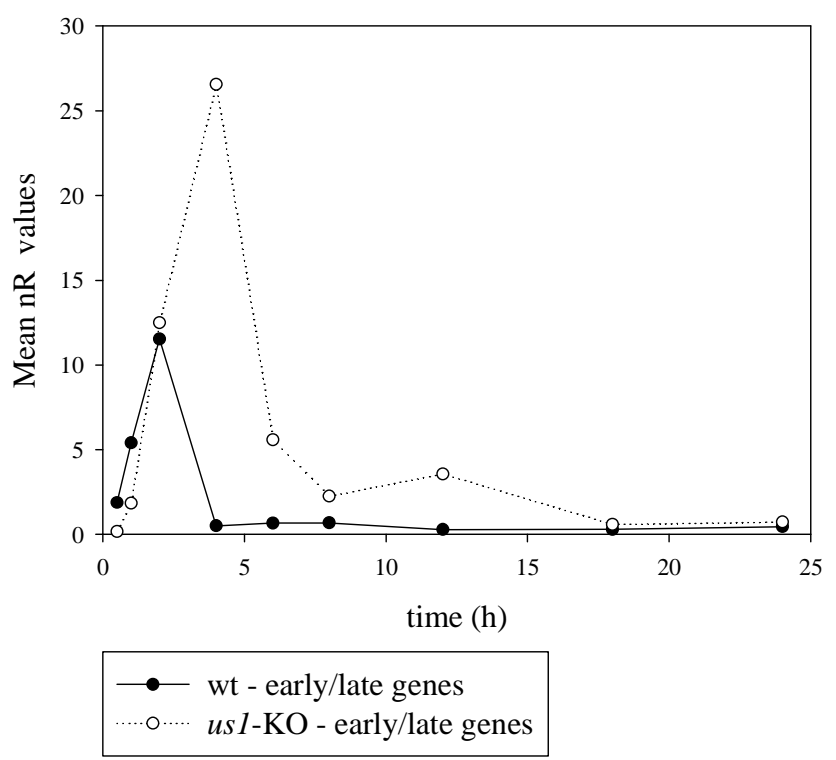

Figure 11. nR values of us1-KO and wt virus Peak of us1-KO is more than 2 times higher than the peak of wt virus
ofnR values. Indeed, at 2 hour $n R$ values were almost the same, but later wtnR values dropped. In contrast, us $1-\mathrm{KO} \mathrm{nR}$ values doubled by 4 hours. Later, amount of mRNA decreasedin the same way as the wt virus (Figure 11). Difference between the effect on early and early/late genes are the followings: no delay was observed in transcription of early-late genes compared to the early genes, where transcription started one hour later. $\mathrm{R}$ values of peaks of usl-KO virus were doubled in both case, in early and earlylate genes, therefore the ratio was the same. However, nR values of early/late genes were around 25 and 12, in us $1-\mathrm{KO}$ and wt virus, respectively, which means much less transcriptional activitycompared to early genes.

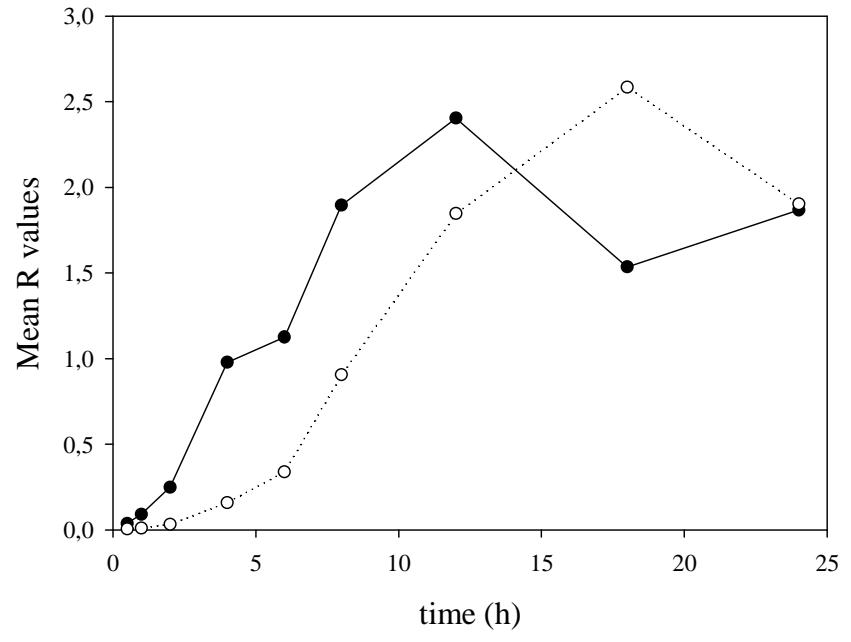

$\longrightarrow$ wt - late genes ....... us 1-KO - late genes

\section{Effect on late genes}

Finally, there was difference between us 1-KO and wt virus regarding late genes. The difference was rather shown in the onset than the rate of expression.

Figure 12. Average of $R$ values of late genes in wt and us1-KO6-hour delay of peak can be observed inus $1-K O$ 
In contrast with the early and early-late genes, $\mathrm{R}$ values peaked around the same value in both viruses. However, delay of onset of transcription and peak could have been seen, approximately 2 and 6 hours, respectively. Highest difference in $\mathrm{R}$ values was at 18 hours, but it could have been derived from the delay of peaks (Figure 12). Ratio of $u s l-\mathrm{KO}$ and wt was below one during the early stage of infection, while it reached one at 12 hour pi, then doubled at 18 hour pi, and dropped by 24 hour (Figure 13). Indeed, it seemed like expression of late genes are lower, if we look at the $n R$ values, where $n R$ value at the peak of wt was double compared to uslKO. Transcription started an hour later in $u s 1-\mathrm{KO}$, and it reached the peak 2 hours later (Figure 14). Based on these observations we can conclude that us 1 gene has enhancing effect on late genes.

\section{Global aspects}

Heatmap visualization allows us to review easily the effect of mutation on a given gene. Table 1 shows the ratio of $\mathrm{R}$ values of $u s 1-\mathrm{KO}$ and wt virus. Mutation increased the transcription to the greatest extent of the following genes: ep0 and $u s 3$, followed by $u l 43$ and $u l 22$.

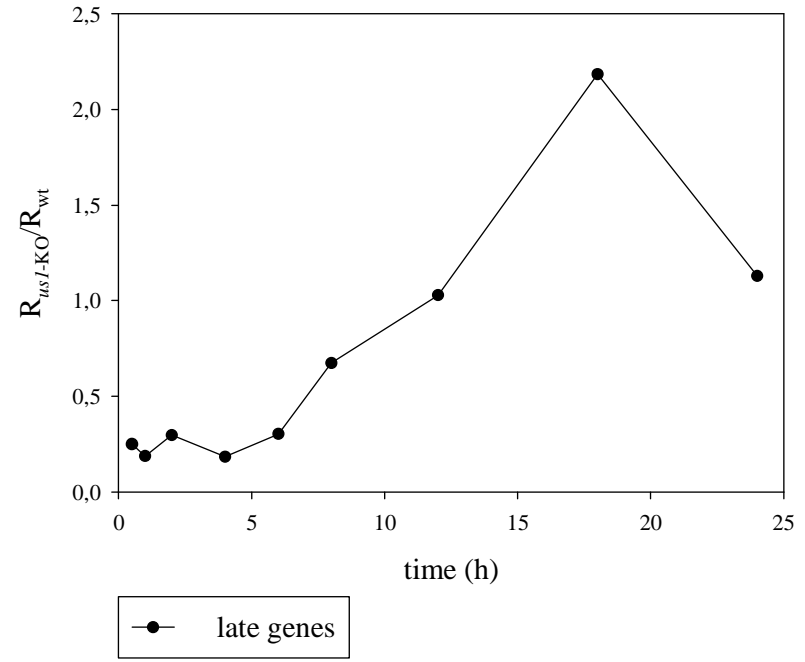

Figure 13. Ratio of average $R$ values of late genes Ratio is lower than one during the early stage of infection, till 12 hours, and get high at 18 hours, then drop again

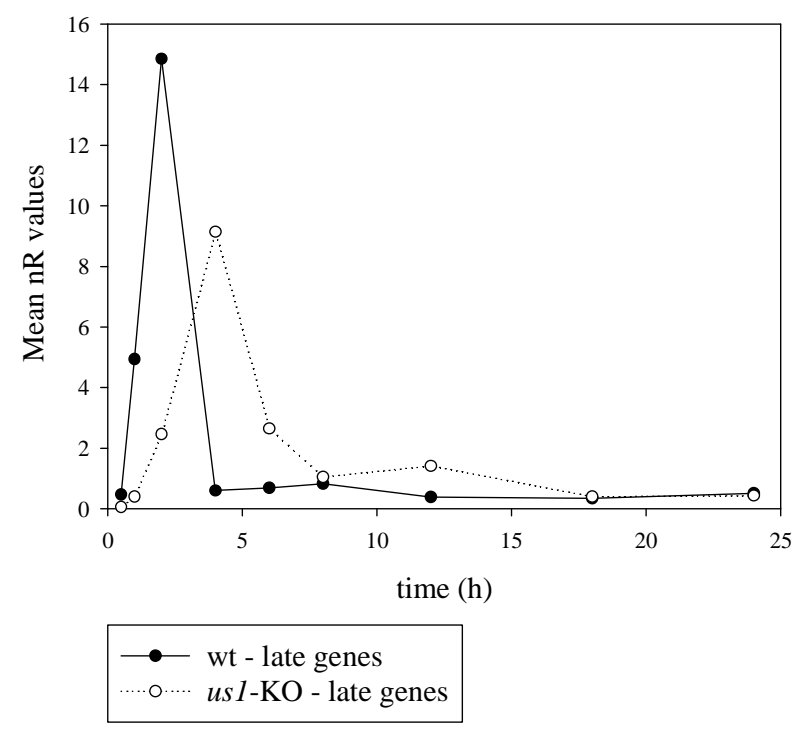

Figure 14. $n R$ values of us 1-KO and wt virusDelay of us1-KO gene expression can be observed, and peak is a bit more than half of peak of wt virus 


\begin{tabular}{|c|c|c|c|c|c|c|c|c|c|}
\hline \multicolumn{10}{|c|}{$\mathrm{R}_{u s l-\mathrm{KO}} / \mathrm{R}_{\mathrm{wt}}$} \\
\hline Gene & $0.5 \mathrm{~h}$ & $1 \mathrm{~h}$ & $2 \mathrm{~h}$ & $4 \mathrm{~h}$ & $6 \mathrm{~h}$ & $8 \mathrm{~h}$ & $12 \mathrm{~h}$ & $18 \mathrm{~h}$ & $24 \mathrm{~h}$ \\
\hline ie180 & $\overline{0,030}$ & $\overline{0,109}$ & 0,207 & 0,204 & 0,266 & 2,819 & 4,129 & 6,547 & 3,342 \\
\hline$p 0$ & 0,069 & 0,218 & ,497 & 2,118 & 4,149 & 10,077 & 12,184 & ,912 & \\
\hline & 0,007 & 0,439 & 4,095 & 410 & 1,351 & & & & \\
\hline 21 & 1,589 & 0,555 & 0,547 & 213 & 245 & & & & 0,8 \\
\hline 23 & 0,011 & 0,011 & ,066 & 087 & 307 & & & & \\
\hline 29 & ,033 & 0,052 & 0,191 & 0,266 & 0,375 & & & & 1,413 \\
\hline 30 & 0,019 & 0,121 & 2,274 & 1,360 & 0,835 & 4,1 & 9 & 08 & 2,785 \\
\hline 50 & 0,015 & 0,086 & & & 152 & & & & 1,240 \\
\hline 52 & 0,188 & 0,245 & 0,685 & 2,489 & 2,721 & & & & 1,371 \\
\hline 154 & 0,012 & 0,018 & 0,211 & 0,154 & 0,151 & 0,490 & 0,527 & 0,765 & 0,404 \\
\hline & 0,024 & 0,258 & ,409 & 873 & 2,078 & & & 12, & 780 \\
\hline ull4 & 0,009 & 0,326 & 1,114 & 0,779 & 0,987 & & 3,032 & & 2,597 \\
\hline 115 & 012 & 0,009 & 0,075 & 0,101 & 0,127 & & 721 & & 0,565 \\
\hline 43 &, 022 & 0,417 & 5 & 0 & 1,225 & & 553 & & 2,2 \\
\hline 153 & 0,429 & 1,347 & 1,007 & 0,488 & 0,706 & & 1,106 & & 1,891 \\
\hline us6 & 0,005 & 0,013 & 0,080 & 0,070 & 0,113 & & 129 & 0,457 & 0,419 \\
\hline 11 & 0,021 & 0,108 & 0,214 & 0,263 & 0,428 & 0 & & & 0,937 \\
\hline 15 & 0,015 & 0,005 & 0,003 & 0,023 & 0,132 & & & & 0,322 \\
\hline ul6 & 0,433 & 0,308 & 0,055 & 0,077 & 0,144 & & & & 0,808 \\
\hline ul10 & 0,043 & 0,023 & 0,071 & 0,117 & 0,244 & & & & 0,444 \\
\hline ul17 & 0,068 & 0,025 & 0,062 & 0,066 & 0,175 & & & & 0,885 \\
\hline ul19 & 0,488 & 0,091 & 0,185 & 0,159 & & & & 517 & 1,563 \\
\hline$u l 22$ & 0,031 & 0,400 & 0,2 & & 0,257 & & & 338 & 3,160 \\
\hline$u l 24$ & 1,929 & 1,246 & 1,430 & 0,264 & 0,512 & & & & 0,948 \\
\hline$u l 32$ & 0,052 & 0,028 & 0,073 & 0,117 & & & & & 1,264 \\
\hline 133 & 0,00 & 0,331 & & & 0,284 & & & & 1,424 \\
\hline ul36 & 0,052 & $\overline{0,061}$ & 0,645 & 0,0 & 0,1 & & & & 1,031 \\
\hline ul37 & 0,305 & 0,034 & 0,205 & 0,021 & 0,225 & & 868 & 78 & 1,414 \\
\hline ul41 & 0,244 & 0,258 & 0,817 & 0,584 & 0,790 & & 98 & 34 & 1,155 \\
\hline ul42 & 0,053 & 0,156 & 0,388 & 0,351 & 0,977 & 1,460 & 1,534 & & 1,673 \\
\hline ul44 & 0,015 & 0,005 & 0,007 & 0,009 & 0,021 & 0,044 & 0,082 & 0,960 & 0,380 \\
\hline ul48 & 0,031 & 0,084 & 0,126 & & 0,195 & & & 2,211 & 1,557 \\
\hline$u l 51$ & & & 0,001 & & & & & & 0,245 \\
\hline LAT & 0,230 & 0,095 & 0,172 & 0,074 & 0,101 & 0,159 & 0,247 & 0,558 & 0,270 \\
\hline AST & $0,1 \angle 4$ & 0,081 & 0,116 & 0,018 & 0,100 & 0,278 & 0,600 & 1,443 & 1,062 \\
\hline
\end{tabular}

\begin{tabular}{|r|}
\hline 12,000 \\
\hline 9,000 \\
6,000 \\
3,000 \\
1,000 \\
0,900 \\
0,800 \\
0,700 \\
0,600 \\
0,500 \\
0,400 \\
0,300 \\
0,200 \\
0,100 \\
0,000 \\
\hline
\end{tabular}

Table 1. Ratio of $R$ values of us 1-KO and wt virus Color-coded ratio of $R$ values indicate whether gene expression of us1-KO or wt virus is higher at a given time point, in case of a particular gene. Scale with the ratios is present on the right side of the table 
Based on these findings we assumed that us 1 interacts with ep0, and in case of absence of $u s l$, there is no inhibition of $e p 0$. Therefore level of $e p 0$ mRNA becomes higher than in case of the wt virus. Interestingly, our previous studies conducted with epO-KO PRV virus showed that expression of $u s l$ was different from all the other genes, because in contrast to other genes its expression was lower in the ep0mutant than in the wt virus atall time points, except from one (at $2 \mathrm{~h} \mathrm{pi)[25].} \mathrm{Thus,} \mathrm{ep0} \mathrm{may} \mathrm{enhance} \mathrm{the} \mathrm{activity} \mathrm{of} \mathrm{usl,} \mathrm{and} \mathrm{in} \mathrm{the}$ absence of ep0, expression of $u s 1$ is low. However, us 1 inhibit expression of ep0. This leads to an assumption, which supposes that epO inhibits its own expression via enhancing the inhibitory effect of $u s 1$. The phenomenon results in precise control of the gene expression cascade. Further, in case of early and early-late genes, till 1 hour pi ratios of $u s 1-\mathrm{KO}$ and wt was lower than one in most of the genes, while ratio of late genes was lower than one till 6 hour pi. Table 2 shows the $\mathrm{nR}$ ratios of $u s 1-\mathrm{KO}$ and wt virus. With this presentation it is possible to eliminate the disturbing effect resulting from differences of DNA replication between the mutant and the wt virus, and to show only the transcriptional changes. However, the resultsare very similar to the $\mathrm{R}$ values. $E p O$ is one of the most affected genes, but $u l 52$ has the highest ratio. Besides, ul9, ul30, ul43, us 3 and $u l 50$ also had high ratios throughout the entire infection. Gene expression of all genes, except from $u l 24$ and $u l 21$, were lower in $u s 1$ KO than wt virus during the first two hours. Later, at 4 hour pi, all genes were transcribed with much higher rate than the wt, except from one gene (ul44). Ul44 was the only one, whose expression was lower during the whole infection in the usl-KO. At 6 hour, most of genes were still transcribed more, except from ul44 and ul51. mRNA levels of most of late genes decreased at 8 hours, which was not the case in early and early-late genes, whose transcription remained high in $u s 1-K O$. Furthermore, $\mathrm{nR}$ values of $u s 6, u l 44$ and $u l 51$ were lower than one at 12 hours, while values of all the other genes were higher. Later during the infection, at 18 and 24 hours, some genes got higher and some stayed lower regardless of any pattern. It is also interesting to show the $n R_{A}$ values (Table 3 ). $n R_{A}$ reflects the rate of change in $n R$ values in two consecutive time points. $\mathrm{nR}_{\mathrm{A}}$ values of wt virus is present in the first half of the table. Steep decrease could have been observed from 2 to 4 hours, followed by a slighter decrease from 8 to 12 hours.However, in usl-KO, this decrease occurred in $\mathrm{nR}$ values from 4 to 6 hours, and from 6 to 8 hours, and another decline was observed from 12 to 18 hours. 


\begin{tabular}{|c|c|c|c|c|c|c|c|c|c|c|}
\hline \multicolumn{10}{|c|}{$\mathrm{nR}_{u s l-\mathrm{KO}} / \mathrm{nR}_{\mathrm{wt}}$} & \\
\hline Gene & $0.5 \mathrm{~h}$ & $1 \mathrm{~h}$ & $2 \mathrm{~h}$ & $4 \mathrm{~h}$ & $6 \mathrm{~h}$ & $8 \mathrm{~h}$ & $12 \mathrm{~h}$ & $18 \mathrm{~h}$ & $24 \mathrm{~h}$ & \\
\hline ie180 & 0,022 & 0,076 & 0,254 & 19,072 & 3,377 & 7,423 & 19,501 & 4,451 & 2,778 & \\
\hline epO & 0,050 & 0,152 & 1,837 & 197,640 & 52,775 & 26,534 & 57,543 & 6,059 & 3,034 & \\
\hline$u l 9$ & 0,005 & 0,305 & 5,025 & 131,548 & 17,190 & 14,526 & 23,555 & 3,759 & 4,520 & \\
\hline$u l 21$ & 1,142 & 0,385 & 0,672 & 19,865 & 3,111 & 0,823 & 3,485 & 0,923 & 0,732 & \\
\hline$u l 23$ & 0,008 & 0,007 & 0,082 & 8,128 & 3,900 & 1,694 & 4,975 & 0,819 & 0,324 & \\
\hline$u l 29$ & 0,024 & 0,036 & 0,235 & 24,844 & 4,772 & 4,353 & 11,313 & 1,741 & 1,174 & \\
\hline ul30 & 0,014 & 0,084 & 2,791 & 126,895 & 10,615 & 10,980 & 20,447 & 3,133 & 2,315 & \\
\hline$u l 50$ & 0,011 & 0,059 & 2,106 & 80,191 & 14,653 & 8,077 & 16,067 & 2,158 & 1,030 & 210,000 \\
\hline$u l 52$ & 0,135 & 0,170 & 0,841 & 232,261 & 34,617 & 18,823 & 13,118 & 4,436 & 1,140 & 180,000 \\
\hline$u l 54$ & 0,009 & 0,013 & 0,259 & 14,409 & 1,918 & 1,290 & 2,490 & 0,520 & 0,336 & 150,000 \\
\hline us 3 & 0,018 & 0,179 & 0,502 & 81,454 & 26,433 & 13,261 & 33,298 & 8,199 & 3,142 & 120,000 \\
\hline ul14 & 0,007 & 0,226 & 1,368 & 72,674 & 12,557 & 11,181 & 14,321 & 1,814 & 2,158 & 90,000 \\
\hline ul15 & 0,009 & 0,006 & 0,092 & 9,417 & 1,614 & 0,840 & 3,406 & 0,732 & 0,469 & 60,000 \\
\hline ul43 & 0,016 & 0,290 & 1,835 & 85,166 & 15,581 & 6,272 & 45,115 & 4,549 & 1,856 & 30,000 \\
\hline ul53 & 0,308 & 0,935 & 1,235 & 45,486 & 8,986 & 1,347 & 5,222 & 2,189 & 1,572 & 10,000 \\
\hline us 6 & 0,004 & 0,009 & 0,098 & 6,574 & 1,438 & 0,255 & 0,608 & 0,311 & 0,348 & 5,000 \\
\hline ull & 0,015 & 0,075 & 0,262 & 24,556 & 5,444 & 1,328 & 4,941 & 2,096 & 0,779 & 2,000 \\
\hline$u l 5$ & 0,011 & 0,004 & 0,003 & 2,133 & 1,676 & 0,159 & 1,530 & 0,170 & 0,267 & 1,200 \\
\hline ul6 & 0,311 & 0,214 & 0,068 & 7,188 & 1,825 & 0,438 & 5,056 & 0,853 & 0,671 & 1,100 \\
\hline ul10 & 0,031 & 0,016 & 0,087 & 10,959 & 3,100 & 0,579 & 1,689 & 0,555 & 0,369 & 1,000 \\
\hline ul17 & 0,049 & 0,018 & 0,077 & 6,181 & 2,227 & 0,785 & 2,995 & 0,801 & 0,736 & 0,800 \\
\hline ul19 & 0,351 & 0,063 & 0,227 & 14,821 & 3,182 & 0,750 & 5,366 & 1,711 & 1,299 & 0,600 \\
\hline$u l 22$ & 0,022 & 0,278 & 0,345 & 49,404 & 3,272 & 4,609 & 12,653 & 5,669 & 2,626 & 0,400 \\
\hline ul24 & 1,386 & 0,865 & 1,755 & 24,638 & 6,506 & 2,928 & 9,451 & 2,669 & 0,788 & 0,300 \\
\hline ul32 & 0,037 & 0,020 & 0,090 & 10,961 & 3,662 & 0,832 & 3,465 & 1,261 & 1,051 & 0,200 \\
\hline ul33 & 0,005 & 0,230 & 0,593 & 22,626 & 3,614 & 1,609 & 8,532 & 1,444 & 1,183 & 0,100 \\
\hline ul36 & 0,037 & 0,042 & 0,791 & 8,484 & 1,904 & 0,848 & 2,983 & 1,135 & 0,857 & 0,000 \\
\hline ul37 & 0,219 & 0,024 & 0,251 & 1,981 & 2,857 & 0,828 & 4,101 & 1,073 & 1,175 & \\
\hline ul41 & 0,175 & 0,179 & 1,003 & 54,503 & 10,046 & 8,702 & 9,438 & 2,267 & 0,960 & \\
\hline ul42 & 0,038 & 0,109 & 0,476 & 32,725 & 12,425 & 3,844 & 7,245 & 1,213 & 1,391 & \\
\hline ul44 & 0,011 & 0,004 & 0,009 & 0,876 & 0,272 & 0,116 & 0,390 & 0,653 & 0,316 & \\
\hline ul48 & 0,022 & 0,058 & 0,154 & 10,206 & 2,480 & 0,692 & 1,824 & 1,503 & 1,294 & \\
\hline ul51 & 0,324 & 0,006 & 0,002 & 9,196 & 0,889 & 1,104 & 0,933 & 0,180 & 0,204 & \\
\hline LAT & 0,165 & 0,066 & 0,211 & 6,924 & 1,281 & 0,419 & 1,165 & 0,379 & 0,225 & \\
\hline AST & 0,089 & 0,057 & 0,142 & 1,638 & 1,274 & 0,732 & 2,832 & 0,981 & 0,883 & \\
\hline
\end{tabular}

Table 2. Ratio of $\boldsymbol{n R}$ values of us 1-KO and wt virus Gene expression in the first 2 hour was low in us1-KO, as indicated by the red color of the cells, but by 4 hour pi ratio of nearly all the genes got higher than one 


\begin{tabular}{|c|c|c|c|c|c|c|c|c|c|c|c|c|c|c|c|c|}
\hline \multirow[b]{2}{*}{ Gene } & \multicolumn{8}{|c|}{$\mathrm{nR}_{\mathrm{A}}$ of $\mathrm{wt}$} & \multicolumn{8}{|c|}{$\mathrm{nR}_{\mathrm{A}}$ of $u s 1-\mathrm{KO}$} \\
\hline & $1 / 0,5$ & $2 / 1$ & $4 / 2$ & $6 / 4$ & $8 / 6$ & $12 / 8$ & $18 / 12$ & $24 / 18$ & $1 / 0,5$ & $2 / 1$ & $4 / 2$ & $6 / 4$ & $8 / 6$ & $12 / 8$ & $18 / 12$ & $24 / 18$ \\
\hline ie180 & 1,537 & 1,034 & 0,045 & 1,143 & 0,467 & 0,314 & 0,878 & 1,512 & 5,356 & 3,481 & 3,400 & 0,202 & 1,027 & 0,824 & 0,200 & 0,943 \\
\hline ер0 & 3,729 & 1,243 & 0,014 & 0,538 & 0,649 & 0,393 & 0,968 & 1,315 & 11,369 & 15,056 & 1,500 & 0,144 & 0,326 & 0,852 & 0,102 & 0,659 \\
\hline$u l 9$ & 1,938 & 1,310 & 0,019 & 1,416 & 0,958 & 0,440 & 2,394 & 0,941 & 117,883 & 21,602 & 0,508 & 0,185 & 0,810 & 0,713 & 0,382 & 1,132 \\
\hline$u l 21$ & 8,143 & 1,895 & 0,069 & 1,254 & 1,393 & 0,319 & 1,187 & 1,304 & 2,748 & 3,304 & 2,032 & 0,196 & 0,369 & 1,352 & 0,314 & 1,035 \\
\hline ul23 & 35,225 & 2,517 & 0,033 & 0,663 & 0,601 & 0,400 & 1,144 & 1,530 & 33,946 & 27,678 & 3,315 & 0,318 & 0,261 & 1,175 & 0,188 & 0,605 \\
\hline$u l 29$ & 15,978 & 2,353 & 1,018 & 0,838 & 0,440 & 0,452 & 1,066 & 1,258 & 24,116 & 15,398 & 1,908 & 0,161 & 0,402 & 1,175 & 0,164 & 0,848 \\
\hline ul30 & 9,788 & 0,478 & 0,019 & 1,589 & 0,552 & 0,581 & 1,570 & 1,949 & 59,490 & 15,926 & 0,868 & 0,133 & 0,571 & 1,082 & 0,240 & 1,440 \\
\hline$u l 50$ & 6,462 & 0,741 & 0,039 & 0,857 & 0,474 & 0,904 & 0,638 & 2,466 & 34,670 & 26,263 & 1,495 & 0,157 & 0,261 & 1,798 & 0,086 & 1,178 \\
\hline$u l 52$ & 4,886 & 1,221 & 018 & 1,019 & 0,961 & 0,871 & 1,461 & 2,876 & 6,154 & 6,046 & 5,004 & 0,152 & 0,523 & 0,607 & 0,494 & 0,739 \\
\hline ul54 & 26,525 & 0,924 & ,037 & 1,128 & 0,462 & 0,621 & 1,054 & 1,571 & 38,576 & 19,032 & 2,072 & 0,150 & 0,310 & 1,198 & 0,220 & 1,016 \\
\hline us 3 & 7,283 & 2,200 & 0,019 & 0,791 & 0,737 & 0,359 & 0,820 & 1,600 & 74,241 & 6,178 & 3,123 & 0,257 & 0,370 & 0,900 & 0,202 & 0,613 \\
\hline ul14 & 2,685 & 1,902 &, 039 & 1,046 & 0,707 & 0,779 & 1,609 & 1,255 & 91,133 & 11,488 & 2,084 & 0,181 & 0,629 & 0,997 & 0,204 & 1,493 \\
\hline ul15 & 45,398 & 3,083 & 0,031 & 1,509 & 0,624 & 0,356 & 0,987 & 1,527 & 30,929 & 46,768 & 3,179 & 0,259 & 0,325 & 1,443 & 0,212 & 0,980 \\
\hline ul43 & 1,713 & 2,278 & 0,051 & 1,061 & 0,859 & 0,345 & 1,014 & 2,523 & 30,960 & 14,434 & 2,354 & 0,194 & 0,346 & 2,479 & 0,102 & 1,030 \\
\hline ul53 & 2,487 & 1,823 & 0,042 & 1,467 & 1,664 & 0,303 & 0,843 & 1,833 & 7,542 & 2,408 & 1,545 & 0,290 & 0,249 & 1,176 & 0,353 & 1,316 \\
\hline us6 & 12,533 & 1,519 & 0,087 & 2,143 & 1,262 & 0,481 & 0,690 & 1,121 & 32,041 & 16,116 & 5,781 & 0,469 & 0,224 & 1,145 & 0,352 & 1,257 \\
\hline ull & 9,584 & 2,317 & 0,083 & 1,173 & 0,984 & 0,354 & 0,855 & 1,262 & 48,723 & 8,063 & 7,739 & 0,260 & 0,240 & 1,318 & 0,363 & 0,469 \\
\hline ul5 & 6,207 & 5,633 & ,019 & 0,258 & 4,550 & 0,136 & 2,238 & 0,676 & 2,060 & 4,899 & 12,736 & 0,203 & 0,432 & 1,307 & 0,248 & 1,067 \\
\hline ul6 & 10,641 & 8,920 & 0,021 & 1,408 & 1,008 & 0,283 & 0,948 & 1,415 & 7,316 & 2,837 & 2,234 & 0,358 & 0,242 & 3,267 & 0,160 & 1,114 \\
\hline ullo & 17,475 & 3,077 & 0,083 & 2,069 & 1,796 & 0,564 & & 1,699 & 9,174 & 16,613 & 10,481 & 0,585 & 0,336 & 1,645 & 0,249 & 1,129 \\
\hline ul17 & 7,853 & 4,113 & 0,124 & 1,005 & 1,342 & 0,506 & 0,986 & 1,703 & 2,809 & 17,887 & 10,035 & 0,362 & 0,473 & 1,932 & 0,264 & 1,564 \\
\hline ul19 & 18,078 & 1,416 & 0,104 & 1,678 & 1,451 & 0,264 & 1,259 & 1,178 & 3,272 & 5,071 & 6,804 & 0,360 & 0,342 & 1,889 & 0,401 & 0,894 \\
\hline$u l 22$ & 2,194 & 4,795 & 0,039 & 3,097 & 0,352 & 0,548 & 0,486 & 2,158 & 27,338 & 5,956 & 5,563 & 0,205 & 0,495 & 1,505 & 0,218 & 1,000 \\
\hline$u l 24$ & 4,636 & 1,075 & 0,363 & 1,088 & 0,829 & 0,431 & 1,412 & 2,028 & 2,894 & 2,180 & 5,096 & 0,287 & 0,373 & 1,392 & 0,399 & 0,599 \\
\hline ul32 & 14,839 & 2,215 & 0,114 & 0,745 & 1,405 & 0,407 & 0,803 & 1,416 & 7,879 & 10,087 & 14,001 & 0,249 & 0,319 & 1,694 & 0,292 & 1,179 \\
\hline ul33 & 6,234 & 1,440 & 0,076 & 2,011 & 0,809 & 0,477 & 1,171 & 1,926 & 265,241 & 3,722 & 2,887 & 0,321 & 0,360 & 2,530 & 0,198 & 1,578 \\
\hline ul36 & 21,914 & 0,452 & 0,052 & 1,677 & 1,116 & 0,556 & 0,984 & 1,204 & 24,870 & 8,427 & 0,556 & 0,377 & 0,497 & 1,955 & 0,374 & 0,909 \\
\hline ul37 & 11,938 & 2,117 & 0,119 & 1,401 & 0,981 & 0,403 & 1,101 & 1,388 & 1,302 & 22,260 & 0,939 & 2,021 & 0,284 & 1,996 & 0,288 & 1,520 \\
\hline ul41 & 6,915 & 1,394 & 0,039 & 1,183 & 0,591 & 0,793 & 0,784 & 2,426 & 7,088 & 7,792 & 2,095 & 0,218 & 0,512 & 0,860 & 0,188 & 1,027 \\
\hline ul42 & 5,735 & 3,768 & 0,076 & 0,948 & 1,043 & 0,422 & 0,876 & 0,892 & 16,261 & 16,512 & 5,197 & 0,360 & 0,323 & 0,795 & 0,147 & 1,023 \\
\hline ul44 & 20,263 & 4,460 & 0,311 & 1,946 & 1,226 & 0,795 & 0,244 & 2,404 & 6,977 & 10,695 & 30,394 & 0,605 & 0,522 & 2,672 & 0,408 & 1,164 \\
\hline ul48 & 14,416 & 2,196 & 0,056 & 1,972 & 0,812 & 0,604 & 0,937 & 1,887 & 37,628 & 5,801 & 3,680 & 0,479 & 0,226 & 1,592 & 0,772 & 1,624 \\
\hline$u l 51$ & 615,820 & 5,035 & 0,015 & 0,769 & 1,976 & 0,784 & 0,780 & 1,178 & 10,561 & 1,557 & 78,454 & 0,074 & 2,456 & 0,662 & 0,150 & 1,336 \\
\hline LAT & 18,232 & 1,732 & 0,091 & 1,263 & 1,298 & 0,336 & 1,255 & 1,428 & 7,287 & 5,535 & 2,989 & 0,234 & 0,425 & 0,934 & 0,409 & 0,846 \\
\hline AST & 5,805 & 1,215 & 0,159 & 1,205 & 1,328 & 0,646 & 0,928 & 1,304 & 3,674 & 3,058 & 1,828 & 0,937 & 0,763 & 2,499 & 0,322 & 1,173 \\
\hline
\end{tabular}

Table 3. $n R_{A}$ values of wt and us1-KO mutant. First table shows the wt, second table shows the us1-KO values. Blue and green indicates decrease compared to the previous time point, while yellow means increase 
This meant a two-hour delay compared to the wild-type virus. Decrease of transcription per one strand of DNA occurred during that period when the DNA replication started (at 4 hour pi in wt, and at 6 hour pi in usl-KO), therefore this phenomenon may be the consequence of the increasing amount of DNA.

I would like to highlight another important result. It is widely known that late genes are transcribed after the onset of DNA replication [70]. I would like to disprove this theory based on our findings. Figure 14 shows that late genes are highly transcribed in the first two hours of infection (in wt virus), while DNA replication started after 2 hour (Figure 3). It is possible that the absolute amount of mRNA is not high, but compared to the amount of DNA, we could observe transcription. Figure 14 shows that expression of late genes starts before DNA replication. It is possible that the observed phenomenon cannot be applied for every virus, but in PRV this seems to be the case.

Finally, we were curious about the differences and similarities in between the homologues of us1 (ICP22) among alpha herpesviruses. Therefore we performed a motif-search, by using a program called MEME (Multiple Expectation Maximization for Motif Elicitation) analysis[71]. Aaron et al. were the first who performed MEME analysis with human herpes viruses (HHV)[72]. We have completed this analysis on other sequences of the above represented members of alpha herpesviruses. MEME analysis motifs are conserved sequence patterns that occurs repeatedly in a group of related sequences. The analysis revealed 10 conserved region in the family of alpha herpes viruses, from which motif 1, 2 and 3, 5 form a core region of the ICP22 protein and represented in all the members of alpha herpesviruses. Based on the MEME analysis, those viruses, which are close relative, showedmore similar motif pattern, than the distant relatives (Figure 15). Furthermore, we performed several computational predictions with the US1 protein sequence in order to assign functions to the conserved motifs.Our results suggest that the core region of the protein contains several conserved hypothetic protein or DNA binding sites and phosphorylation sites, from which some sites have been confirmed in the HHV and VZV by experimental studies[73-75], but has not been demonstrated in PRV. 


\section{Name}

Human herpesvirus 1

Cercopithecine herpesvirus 2

Varicella zoster virus

Pseudorabies virus Ka strain

Felid herpesvirus 1

Equid herpesvirus 1

Bovine herpesvirus 1

Anatid herpesvirus 1

Gallid herpesvirus 2
Combined $p$-value

$1.94 \mathrm{e}-189$

$1.20 \mathrm{e}-165$

$6.78 \mathrm{e}-101$

$2.90 \mathrm{e}-87$

$2.13 e-96$

1.10.e-104

1.03.e-78

$2.46 \mathrm{e}-88$

$2.15 \mathrm{e}-74$

Figure 15. List of aligned alpha herpesviruses, and the dendogram of amino acid motifs of ICP22 orthologs in the alphaherpesvirinae virus family based on MEME (Multiple Expectation Maximization for Motif Elicitation) analysis 10 motives were found withthe analysis when we compared the herpesviruses shown on the left side

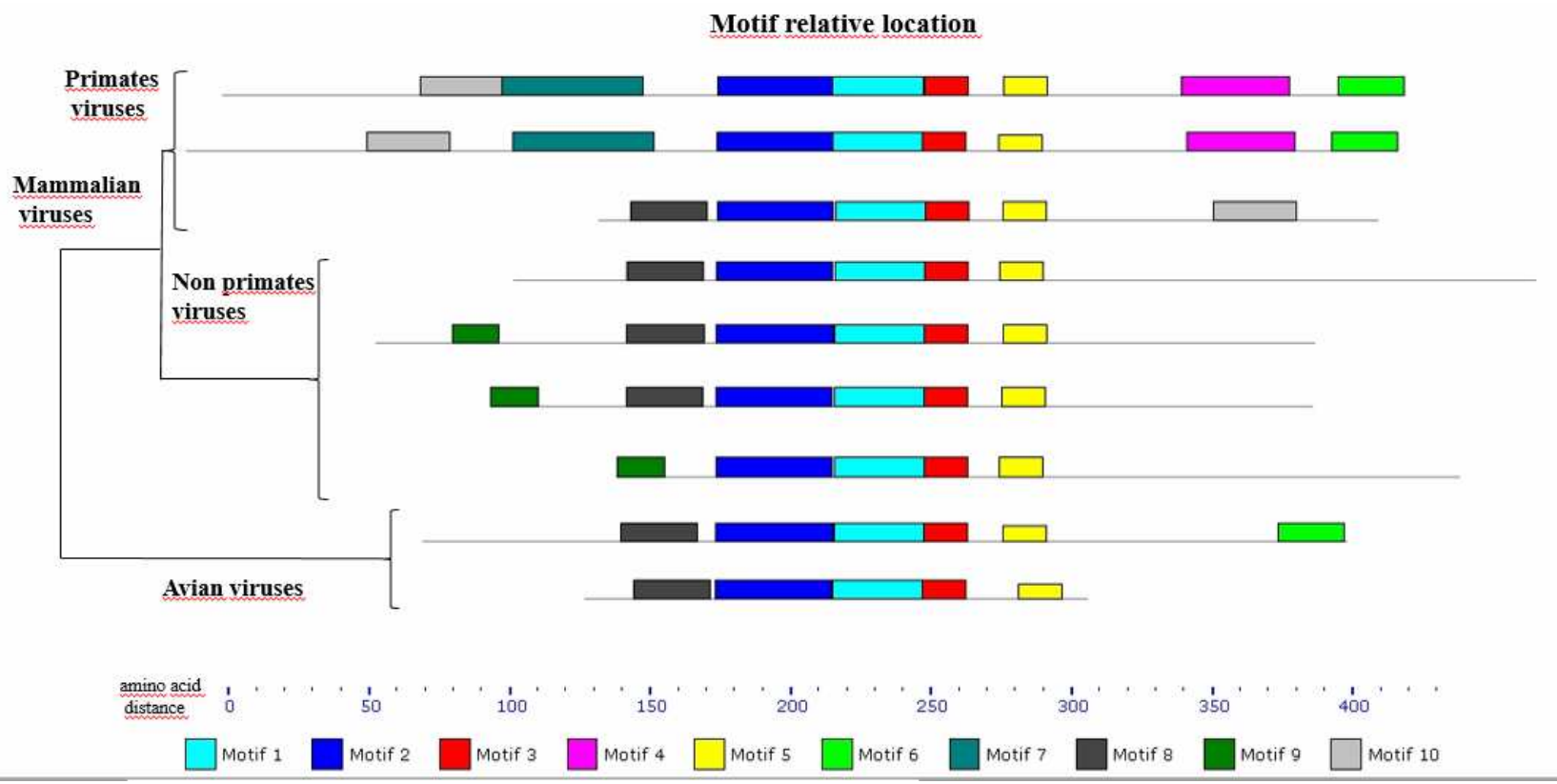

\section{Study of different viral loads on gene expression in wild-type virus}

During our work we studied the effect of different viral loads on gene expression by using real-time RT-PCR assay. We have applied two different amount of virus, $0.1 \mathrm{pfu}$ and 


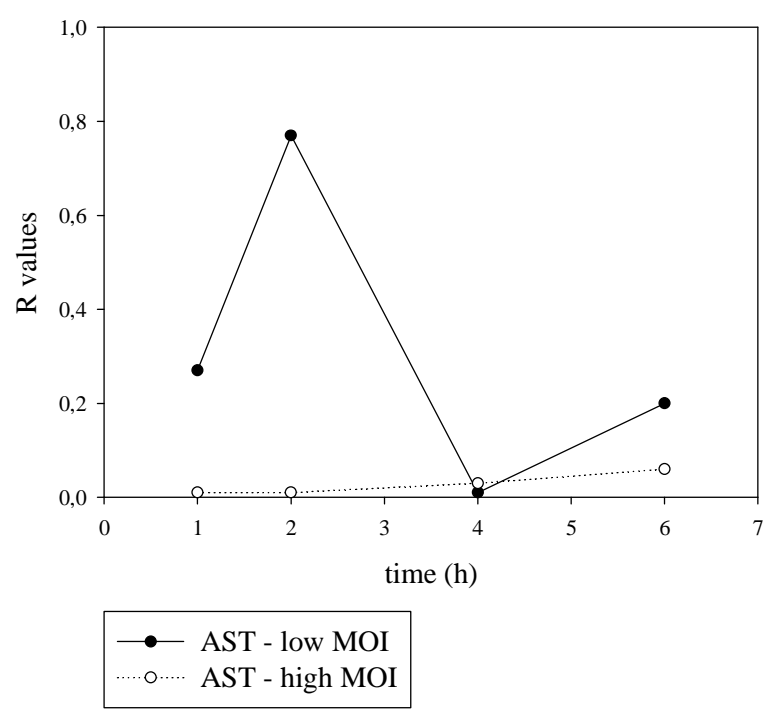

Figure 16. $R$ values of AST in low and high MOI infection Level of AST was much higher during the low MOI infection

10pfu(low- and high-MOI). Our analysis revealed a significant dependence of the gene expression on the MOI in most of the genes.Albeit the differencein the infectious dose in the two parallel experimentswas 100-fold, an individual cell was infected by

10 times more virus particles in the high-MOI than inthe low-MOI experiment $\left(5 \times 10^{7}\right.$ versus $5 \times 10^{6}$ infected cells), because in the lattercase approximately $90 \%$ of the cells remained uninfected. Therefore we have applied two correction factors in order to reliably compare the gene expression in the two experiments. First, we used 10-fold multiplication for the lowMOI experiment, and we have applied another correction factor, namely we have divided the $\mathrm{R}$ values of high MOI experiment with 10 to extrapolate to the gene expression per a certain amount of DNA.

Further I would like to show the gene expression in the early stage during the infection. In the first $2 \mathrm{~h}$, viral DNA replication has not yet been started, and the copy number of viral genomes in a cell therefore corresponds with the infectious dose. During this setup, we found that the mRNA levels of most examined PRV genes were higher in the cells infected with the high MOI than in those infected with the low MOI at both $1 \mathrm{~h}$ and $2 \mathrm{~h}$ pi. This was not unexpected since in the former case viral DNAs were represented approximately 10-fold higher proportion in an average infected cell. Exceptions to this were the transcripts of $u l 1$, $u l 33$, and $u l 51$ at $1 \mathrm{~h}$ pi, and $u l 36, u l 38, u l 43$, and $u l 48$ mRNAs at $2 \mathrm{~h} \mathrm{pi}$, and at both $1 \mathrm{~h}$ and $2 \mathrm{~h}$ : ie180 and ul30 mRNAs, as well as LAT and AST. However, the expression levels normalized to the genome copy number (using R/10 values in the high-MOI infection) showed an inverse pattern: only a few genes were expressed at higher quantity in the highMOI than in low-MOI infection. 


\begin{tabular}{l|ccccr} 
Gene & $1 \mathrm{~h}$ & $2 \mathrm{~h}$ & $4 \mathrm{~h}$ & $6 \mathrm{~h}$ & \\
ie180 & 0,362 & 1,000 & 0,893 & 0,755 & 14,000 \\
ep0 & 4,250 & 2,440 & 0,734 & 0,287 & 3,500 \\
ul54 & 7,500 & 2,500 & 2,282 & 1,485 & 0,875 \\
us1 & 6,000 & 1,429 & 13,600 & 1,781 & 0,219
\end{tabular}

Table 4. Ratio of $R$ values of high-MOI and low MOI infections in ie180, ep0, ul54 and us1 gene. Except from ie180, expression of all the genes were higher in the high-MOI infection than in the low-MOI infection

AST was expressed significantly higher in the cells infected with low MOI than in those infected with high MOI $\left(\mathrm{R}_{\text {low MOI }} / \mathrm{R}_{\text {high MOI }}=111\right.$-fold at $1 \mathrm{~h}$, and 298 -fold at $2 \mathrm{~h}$ pi) (Figure 16.). The expression rate of a single genomic region encoding AST was even 10 times higher (1 h: 1110-fold and 2 h: 2980-fold) in the low-dose infection. In the high-dose infection, 6 of 37 genes (ie180, ul36, ul50, ul54, us 1 , and ul24) exhibited higher expression levels at $1 \mathrm{~h}$ than at $2 \mathrm{~h}$ pi. It should be noted that three of them (ie180, usl and ul54) are regulatory genes. The fourth regulatory PRV gene, ep0, is expressed at a very high level during the first $2 \mathrm{~h}$ in the high-MOI infection $\left(\mathrm{R}_{1 \mathrm{~h}}=1.87, \mathrm{R}_{2 \mathrm{~h}}=2.05\right)$. Apart from ep0, $u l 5\left(\mathrm{R}_{2 \mathrm{~h}}=1.2\right)$ was the only gene that was expressed at a higher extent in the early stages of infection than at $6 \mathrm{~h}$ pi in the high-MOI experiment. The iel 180 gene is the only one that was expressed in a higher amount at $1 \mathrm{~h}$ than at $2 \mathrm{~h}$ pi under both experimental conditions (Figure 17). Overall, it seems like the 4 regulatory genes were expressed at relatively high level before the onset of DNA replication in the high-MOI infection, which was different from the low-MOI infection, with the exception of the ie180gene (Table 4). We think that the reason for the higher expression of regulatory genes at the onset of viral DNA replication in the high-MOI infection is that more regulatory proteins are needed for multiplication of higher copy number of the viral genome. The rate of change in gene expression from $1 \mathrm{~h}$ to $2 \mathrm{~h}$ time point $\left(\mathrm{R}_{2 \mathrm{~h}} / \mathrm{R}_{1 \mathrm{~h}}\right)$ was higher in more than two-third of the PRV genes (25/37) in the low-MOI than in the highMOI infection. The proportion of AST to ie180 mRNA molecules $\left(\mathrm{R}_{\mathrm{AST}} / \mathrm{R}_{\text {iel80}}\right)$ was 0.47 at 
$1 \mathrm{~h}$ pi, and 4.72 at $2 \mathrm{~h}$ pi in cells infected with the low MOI, while this ratio was extremely low ( 0.01) at both $1 \mathrm{~h}$ and $2 \mathrm{~h}$ pi in the high MOI infection (these data are only 

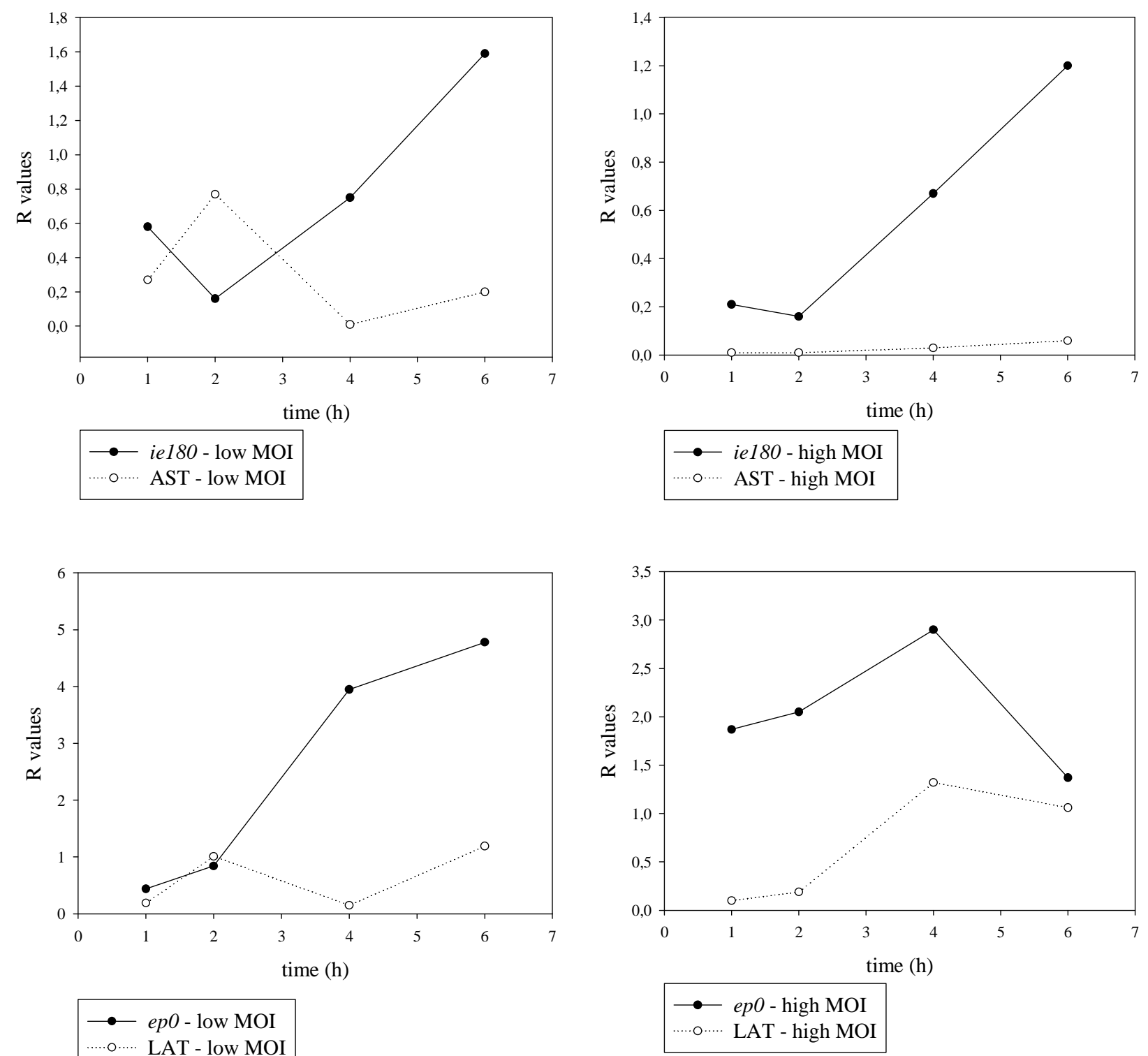

Figure 17. Expression of ie180 and its antisense pair, AST, and ep0 and its antisense pair LAT during low- and high-MOI infection Graph in the upper left corner shows the competition of ie180 and LAT during the low-MOI infection, while the upper right corner shows that high amoun of ie180 transcript inhibit the expression of AST. EpO was expressed higher during the high MOI infection in the early stages, but LAT was the opposite, its expression was lower. 
semi-quantitativebecause the primer efficiencies in the RT reaction are not necessarily equal for the two transcripts). Thus, the proportion of AST to ie180 mRNA was 39-fold higher at 1 $\mathrm{h}$ timepoint and 293-fold higher at $2 \mathrm{~h}$ timepoint in the low-MOI than in the infection (Figure 17).The amount of AST was very high in the early stages of PRV infection, it even significantly exceeded the level of ie180 mRNAs at $2 \mathrm{~h}$ pi in the low-MOI infection, while the amount of AST and also its ratio to ie180 mRNA wereextremely low in the high-MOI infection. Moreover, ie180 mRNA was expressed significantly higher extent in the low-MOI experiment, despite the fact that the copy number of PRV DNA was 10 times lower in an infected cell during the low-MOI experiment. This is very important because IE180 is a DNA-binding protein. We think that this observation reveals an important regulatory mechanism of the herpesviruses, the following: in a high-titer infection, the virus initiates a lytic infection in a cell, while in a low-titer infection, the virus has two choices: establish latent state or enter into lytic cycle. The molecular mechanism of this phenomenon might be based on the interaction of $i e 180$ gene and AST at both the transcription and translation levels: (1) The IE180 protein might exert a negative effect on the synthesis of AST, such as in LAT in HSV [76] by binding the promoter of the antisense transcript. (2) Furthermore, the complementary transcripts might influence each other's expression by RNA-RNA interaction. During an infection with lower amount of virus, the two transcriptsexhibit a complementary expression pattern, which indicates a competition between the two transcripts. In an infection with larger quantity of virus, however, the high initial amount of ie180 gene product inhibits the expression of AST.The significance of this infection strategy could be that, in the case of a low-amount infection, the virus has no chance to invade the host cells; therefore, it is better to hide against the immune surveillance. The ep0 gene was expressed in higher quantity at both $1 \mathrm{~h}$ timepoint (4.22-fold) and $2 \mathrm{~h}$ timepoint (2.43-fold) in the high-MOI infection than in low-MOI infection, which is in contrast with LAT, its antisense partner, whose expression level ep0 mRNA molecules were 8.33-fold higher at $1 \mathrm{~h}$ pi and 13.05-fold higher at $2 \mathrm{~h}$ pi in the low-MOI than in the high-MOI experiment, although, unlike AST, LAT is abundantly expressed in the high-MOI infection (Figure 17). Accordingly, similarly to AST, LAT is expressed in a significantly higher proportion compared to ep 0 mRNA in the low-MOI infection during early stages, which may also be important as concern of the replication strategy of the virus. Our analyses additionally 
showed that AST and LAT are, at least partly, expressed independently from each other, which supports the existence of separate elements controlling the expressions of the two antisense transcripts. Indeed, AST was suggested to be controlled by an antisense promoter (ASP) localized in the outer regions of inverted repeats [77].At $4 \mathrm{~h}$ pi the transcript levels of more than three-quartersof the PRV genes (28/37) were still higher in the high MOI infection than in the low MOI infection. However, $\mathrm{R}_{\mathrm{A}}$ values (rate change in the expression level) of about two-third of the viral RNAs was higher in the low-MOI than in the high-MOI infection (24/37 from $2 \mathrm{~h}$ to $4 \mathrm{~h} \mathrm{pi}$, and 25/37 from $1 \mathrm{~h}$ to $4 \mathrm{~h}$ pi). In the low-MOI infection, at 4 hour timepoint, levels of 5 transcripts ( $u l 5, u l 44, u s 1$ and $u s 6)$ were less than $10 \%$ ofthose in the high-MOI infection. All of theexamined us genes were expressed significantly lowerlevel in the low-titer than in the high-titer infection at $4 \mathrm{~h}$ pi.There were significant decreases in the quantities of bothAST and LAT in the low-titer infection at $4 \mathrm{~h}$ pi relativeto the $2 \mathrm{~h}$ values (AST: 59-fold decrease, and LAT: 7-fold decrease). We could explain this phenomenon by thenegative effect of regulatory genes on their antisensepartners. Regulatory genes are upregulated at the onsetof DNA replication (in order to facilitate this process), which exerts inhibitory effect on the expression ofAST and LAT. In contrast, amount of antisense transcripts increased in the high-MOI infection (AST: 11-fold increase, and LAT: 7-fold increase) from 2 hour pi to 4 hour pi. However, while LAT was expressed at highlevel $(\mathrm{R}=$ 1.3) under the high-MOI conditions, the ASTexpression remained extremely low $(\mathrm{R}=0.013)$ in thisperiod of infection. The amount of the ie180 transcriptwas practically unchanged from $2 \mathrm{~h}$ to $4 \mathrm{~h}$ under either infection conditions. There was a4.7-fold increase in the ep0 mRNA level within the 2 hto $4 \mathrm{~h}$ infection period $\left(\mathrm{R}_{4 \mathrm{~h}} / \mathrm{R}_{2 \mathrm{~h}}\right)$ in the low-MOI infection, as compared with only 1.4 in the high-MOI experiment (Figure 17).On average, amount of mRNAs in the low titer infectionbecame higher than those in the high-infection titer by $6 \mathrm{~h}$ pi in more than half of the PRV genes (22/37). Weassume that the reason for this might be that the ie180gene, the major coordinator of gene expression, wasexpressed at higher levels at 4 and $6 \mathrm{~h}$ pi at low-MOIthan at high-MOI infection. Moreover, in the high-MOIinfection the amount of AST reached almost 30\% of thetranscript level in the low-MOI infection, while LAT wasexpressed at approximately the same level under the twoinfection conditions at $6 \mathrm{~h}$ pi (Figure 17). Genes expressed atlower levels in the low-doseinfection appeared to beclustered on adjacent genomic locations. Eachgene and the two antisense transcripts were 
expressed athigher rates $\left(\mathrm{R}_{\mathrm{A}}\right.$ values) within the $4 \mathrm{~h}$ to $6 \mathrm{~h}$ period inthe low-MOI than in the high-MOI infection withoutexception. In the high-MOI infection,11 genes and LAT peaked at $4 \mathrm{~h}$ within the 6-h examination period, while in the low-MOI infection only the us 3transcript had a slightly lower $\mathrm{R}$ value at $6 \mathrm{~h}$ than at $4 \mathrm{hpi}$. The us 3 gene was the only one among the 70 PRVgenes which was expressed at a higher level at $4 \mathrm{~h}$ than at $6 \mathrm{~h}$ pi in another study. Intriguingly, the epO mRNAsreached a 3.5-fold higher level in the low-dose than inthe high-dose infection in an average cell at $6 \mathrm{~h}$ pi.Furthermore, at $6 \mathrm{~h}$ pi the $u l l$ and $u l 51$ genes wereexpressed at an approximately 10 times higher level under the low-MOI than under the high-MOIconditions.Most genes were expressed at a lower level in a cell in the low-MOI experiment in the first $4 \mathrm{~h}$ of infection, but more than half of these gene products surpassed the high-MOI values by $6 \mathrm{~h}$ pi. All genes were expressed at a higher rate $\left(\mathrm{R}_{\mathrm{A}}\right)$ within the $1 \mathrm{~h}$ to $6 \mathrm{~h}$ period of infection in the low-titer experiment, except for ie180 and the two antisense transcripts. The quantities of ie 180 mRNAs were similar in the two experiments, except at 1 $\mathrm{h}$ pi, where the level of the transcripts was 2.8-fold higher in the low-MOI infection. Thus, the amount of total ie180 transcript in an infected cell appears to be under strict control, independently of the initial infection conditions. In contrast, the expression of the epO gene differed basically in the two experiments. In the high-MOI experiment, the amount of epO mRNAs was high from the first hour of infection, and its expression even declined by $6 \mathrm{~h}$ in the high-MOI infection, while the amount of these transcripts rapidly increased throughout the 6-h infection period in the low-dose infection, and reached a 3.5-fold higher level compared to that of the high-dose infection by $6 \mathrm{~h}$ (Figure 17). The ratio of sense and antisense transcripts during the 6-h infection period displayed intriguing patterns. First of all, in the high-MOI infection the amount of AST and its ratio to ie180 mRNA were very low throughout the 6-h infection period. We demonstrated an inverse relationship in the expression kinetics of ie180 mRNA and AST and also ep0 mRNA and LAT in the low-MOI infection; however, we did not observe this inverse relationship between the complementary transcripts under the high-MOI conditions. 


\section{Neuronal labeling with recombinant pseudorabies virus}

\section{Timer viruses}

Virus-based neuron labeling systems has limitations. For instance, it is very difficult to prevent cell-damaging effect of herpesviruses. Therefore it was needed to develop a method, which helps to indicatethe damagingeffect. The cells are alive during the early stages of infection, therefore it is not possible to differentiate between infected and non-infected cells by electrophysiological methods. If a virus is injected to the anterior chamber of the eye of a given animal, it spread towards CNS, but we cannot determine the exact status of infection, whether the neurons are physiologically intact or not. Therefore we have developed viruses, which express two different fluorescent proteins. One of the protein is green (membranebound green fluorescent protein, VAMP-GFP, primary fluorescent protein), and expressed three hours after the infection of the cell, during the early stage. The other protein is red (soluble Discosoma Red2 from Discosoma species, DsRed2, secondary fluorescent protein), and expressed 10 hours after infecting the cell (Timer viruses). Both fluorescent proteinexpressing gene is driven by CMV promoter. New viral particles are produced during the 7 hour time difference. At $3 \mathrm{~h}$ pi the cells become green, at this point the cells are still alive, the cytotoxic effect of the virus are not present, therefore the condition of cells are suitable for
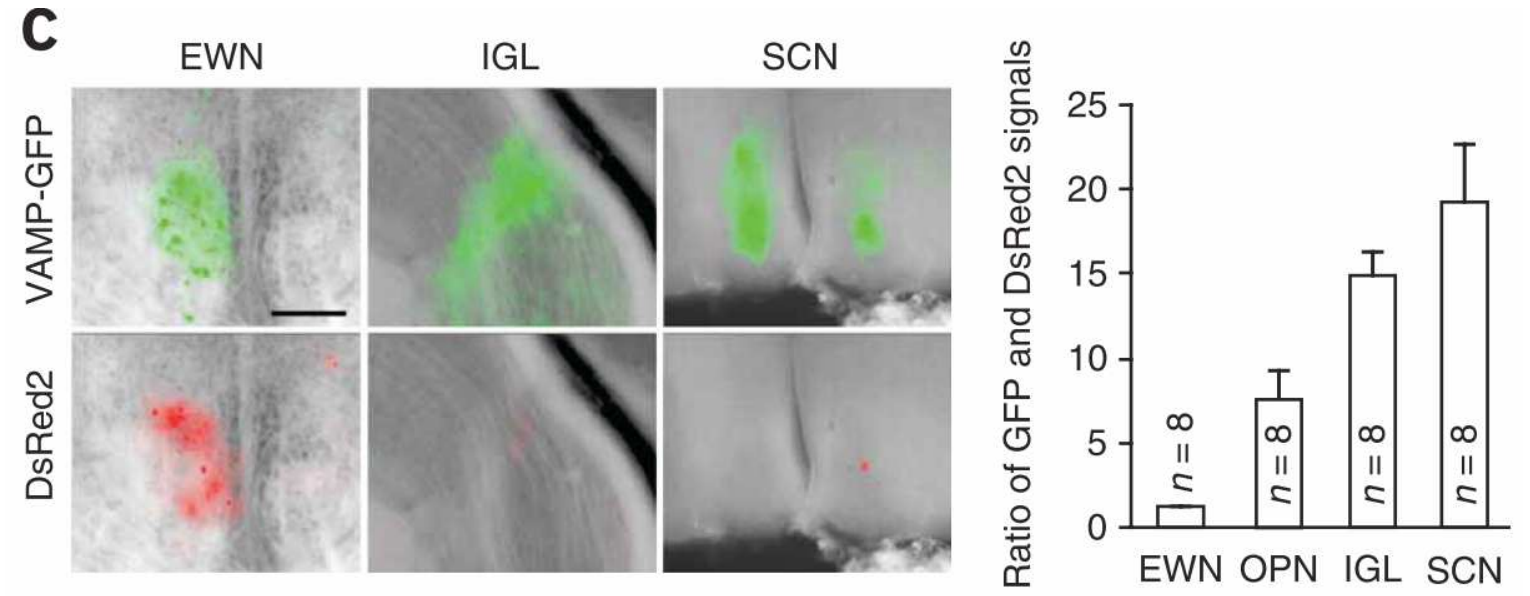

Figure 18. Appearance of red and green fluorescent protein on the way along the pupillary reflex pathway. At the first station both red and green color are present, while the following station only green color can be seen. Ratio of GFP and DsRed2 is present on the right side of the figure 
starting the electrophysiological measurements. By $10 \mathrm{~h}$ pi the appearance of red color indicates the end of measurement, when the virus had already damaged the cells. Further, we would have liked to test whether the time-shift is present in vivo. For this purpose, timer virus was injected into the anterior chamber of the right eye in mice, and analyzed the brain nuclei of the pupillary reflex pathways $3.5 \mathrm{~d}$ after infection. In the Eddinger-Westphal nucleus (EWN), which is the first station of the viral spread in the brain, the expression of GFP and DsRed2 was similar (green:red ratio, $1.2 \pm 0.046, \mathrm{n}=8$ ). In contrast to the EWN, GFP levels were higher compared to DsRed2 in the olivarypretectal nucleus (OPN; green:red ratio, $7.5 \pm 2, \mathrm{n}=8$ ), inter-geniculate leaflet (IGL; green:red ratio, $14.896 \pm 1.33, \mathrm{n}=8$ ) and the suprachiasmatic nucleus ( $\mathrm{SCN}$; green:red ratio, $19.27 \pm 3.4, \mathrm{n}=8$ ), which are one or two steps further in the retrograde route ofthe virus. These results confirmed that GFP can be detected earlierthan DsRed2 in vivo.

In order to estimate the time delay between the appearance of GFP and DsRed2 fluorescence in vivo, we isolated the contralateral retina $30 \mathrm{~h}$ after lateral geniculate nucleus infection and performed three-dimensional-tile, time-lapsed two-photon imaging of the green and red signals. Only few ganglion cells were labeled at the beginning of the imaging session.We only analyzed those cells, which became green and later red during the experiment and therefore were not fluorescent at the time when we isolated the retina.

$\mathrm{Oh}$

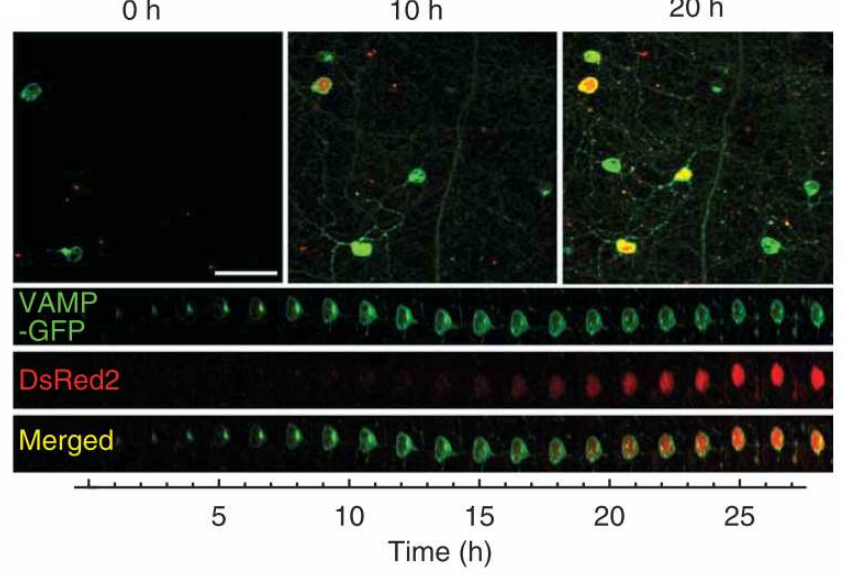

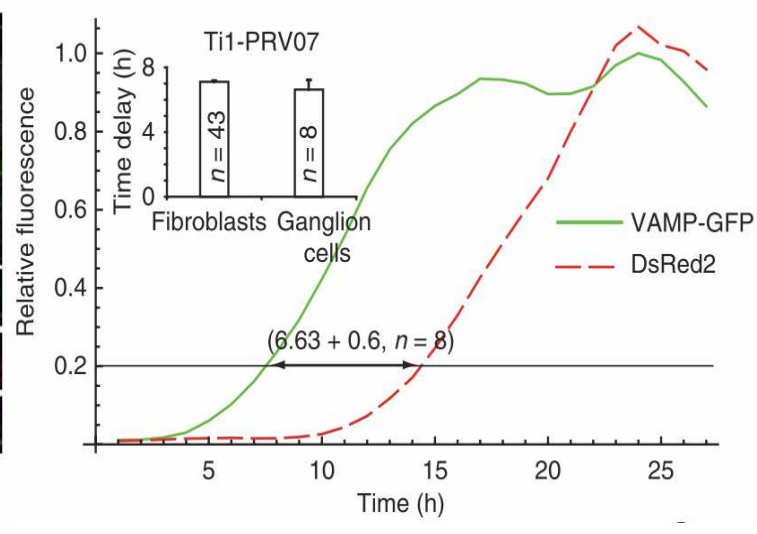

Figure 19. Imaging of expression of GFP and DsRed2 in vivo.DsRed appears in the ganglion cells approximately 7 hours later than GFP 
Similar to cultured cells, the expression of DsRed2 in retinal ganglion cells was delayed by 7 $h(n=9$, Figure 19).

\section{Activity-sensor expressing viruses}

Activity of neurons is associated with change of $\mathrm{Ca} 2+$ levels in the cytoplasm. We have constructed PRVs, which contain chimera molecules emitting yellow light when $\mathrm{Ca} 2+$ level changes. We tested whether this PRV mutant would be a suitable tool for monitoring $\mathrm{Ca} 2+$ concentration changes evoked by pharmacological or physiological stimulation in neurons. We injected the mutant into either the anterior chamber of the right eye or into the primary visual cortex (V1) of mice and tested putative retrogradely labeled retinal ganglion cells for TN-L15 expression in the contralateral eye. To reach these ganglion cells, the virus would need to travel retrogradely through at least one (from V1 through the lateral geniculate nucleus) or at least three (from the anterior chamber via the pupillary reflex pathway) synapses. Retina was isolated, and citrine and CFP fluorescence was measured by two-
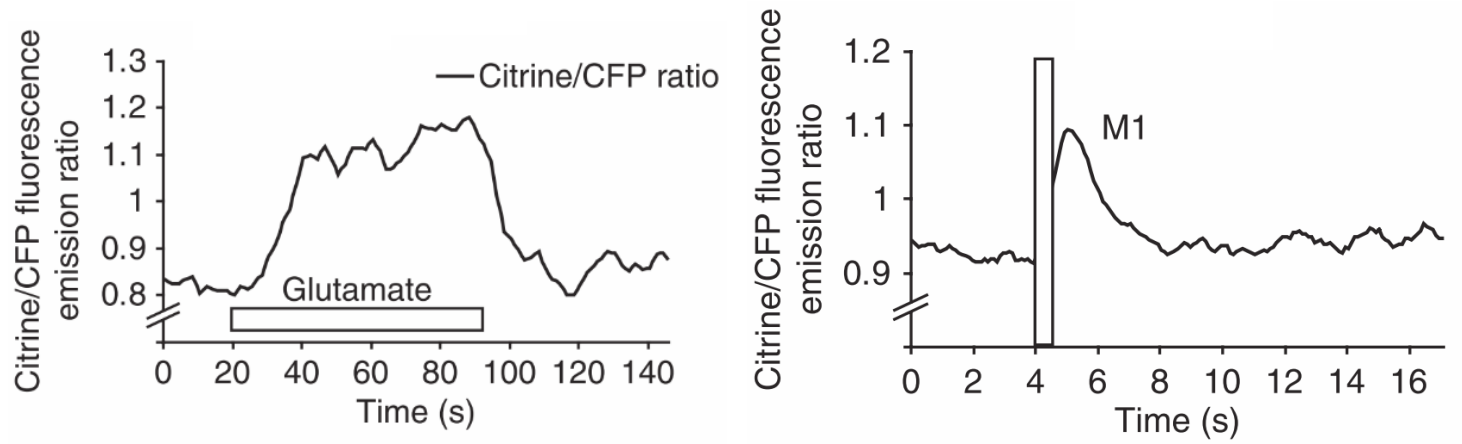

Figure 20. Glutamate and light stimulation of activity-sensor expressing retinal ganglion cells Both stimuli increased the citrine:CFP ratio

photon microscopy. Labeled ganglion cells was activated by puff application of glutamate and light stimulation. When TN-L15 is illuminated with a two-photon laser, a rise in Ca2+ concentration leads to an increase in citrine fluorescence and decrease of CFP fluorescence owing to FRET. Both method increased the citrine:CFP fluorescence ratio, andM1 type of ganglion cells were responsive to light stimulation (Figure 20). 
Combination of Timer and Activity sensor viruses resulted in a virus, which has activitysensor as primary fluorescence protein. DsRed2 remained the secondary fluorescence protein. With using this virus we showed that the physiological state of the infected cells did notsubstantially change during the $7 \mathrm{~h}$. Four days after injecting the combined virus into the anteriorchamber, we removed the contralateral retina and monitoredlight-evoked $\mathrm{Ca} 2+$ changes from ipRGCs by FRET. We repeatedthe recordings every hour until the appearance of the red fluorescence. Light-evoked $\mathrm{Ca} 2+$ responses were similar before the onset ofred fluorescence (Figure 21).

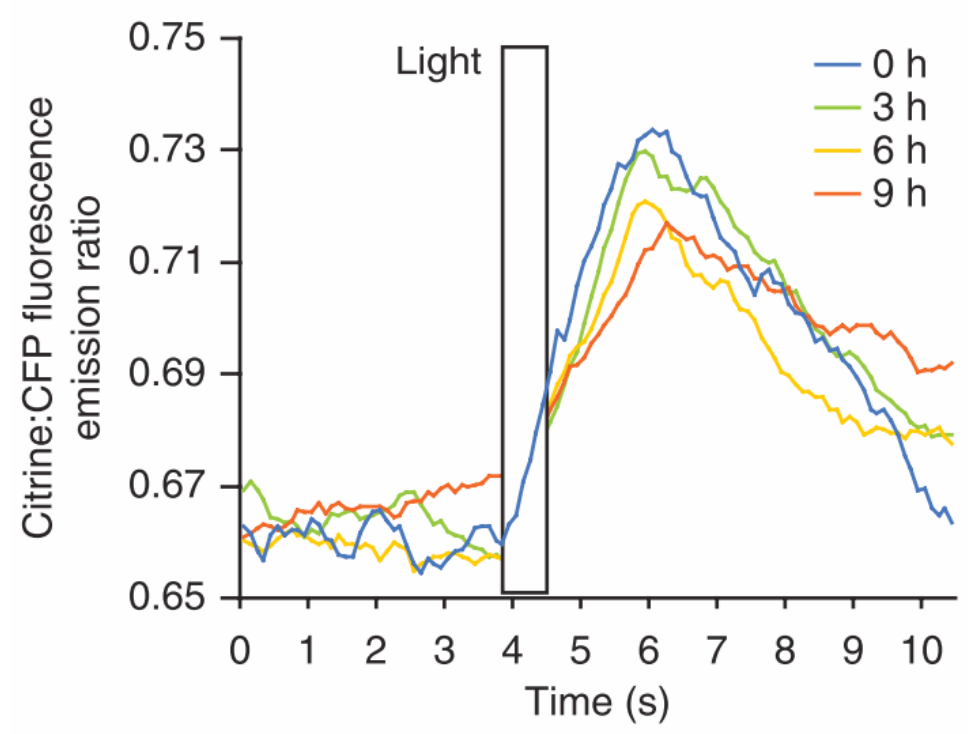

Figure

21.Citrine:CFP ratio after light stimulation of combined virus infected cells on time scale After 9 hours,

\section{DISCUSSION}

\section{Effect of us 1gene mutation on DNA replication and gene expression in PRV}

In my PhD I was studying the function of us 1 gene, which is one of the four regulatory gene of PRV. These genes, ie180, ep0, us1 and ul54 are responsible for precise control of gene expression of PRV. They probably cooperate in regulation of transcription cascade of PRV, but the exact mechanism and pathway has not been known yet.Therefore we would have liked to reveal these connections via studying the knock-out of each regulatory gene. Ie180 is essential for replication and propagation, therefore knock-out mutation of ie 180 does 
not exist. Our group has already studied the effect of deletion of ep 0 , and experiments with the $u l 54-\mathrm{KO}$ mutants are in progress. Usl-mutant was not known in the literature. Therefore, first, I constructed a mutant, which contains CMV-driven GFP expression cassette in the us 1 gene. Then we have infected epithelial cells, followed by using reverse transcription and realtime PCR technique in order to find out the differences and similarities in gene expression of us 1-KO mutant and wild-type virus. We have applied this techniques earlier during research, but we haven't studied the DNA replication. During my work, I have used real-time PCR technique to compare the DNA replication of $u s l-\mathrm{KO}$ and wild-type virus. We have used new approach to describe the gene expression. Briefly, we have normalized the relative expression ratio of mRNA to the relative expression ratio of DNA, therefore we got a value, which describes the gene expression per DNA molecule. Both the gene expression studies and the DNA analysis revealed that usl gene has enormous impact on global scale. First, onset of DNA replication was 4 hours late in $u s l-\mathrm{KO}$ mutant than in the wild-type virus. Therefore we can conclude that US1 protein is required for the start of DNA replication, but the virus has other pathways to perform DNA replication. Therefore US1 protein is not absolutely necessary for DNA replication. However, the dynamic of change in level of DNA are very similar except from the delay. Further, we have evaluated the effect of mutation on early, early/late and late genes. During the first few hours, gene expression of most genes was much lower in $u s 1-\mathrm{KO}$ mutant than in wild-type virus. Thus, we can conclude that US1 protein is essential for the accurate start of gene expression, and in the absence of usl, transcription is late.After, the transcription of different kinetic classes became different. Expression of some of the early and early/late genes increasedfrom 2 to 6 hours in the usl$\mathrm{KO}$ virus compared to wild-type, while others remained low, so as expression of most of late genes. Actually, RNA level of late genes remained lower in the mutant than in the wild-type virus till 8 hours. This was followed by a transitional period, when expression of most of early and early/late genes got higher in $u s l-\mathrm{KO}$, and RNA level of some of late genes became higher too. From 18 hourstranscription of all kinetic classes was higher in usl-KO than in wild-type virus. Thus, function of US1 is distinct considering different time points: during the early stage of infection US1helps starting the transcription, it has a stimulating effect. Later, US1 became inhibitory, and this inhibition affected mostly early and early/late genes, and also late genes, to a lesser extent. Based on only the expression data we cannot tell 
the exact interactions between regulatory genes, therefore further studies are needed to find out these relationships. To summarize the function of us 1 : it is very complex, depending on the time of infection and the kinetic class.

We have made another important observation regarding the relationship between onset of DNA replication and onset of transcription of late genes. In the literature it is widely accepted that DNA replication triggers the expression of late genes. However, as I mentioned before, we have normalized the relative expression ratio of each gene to the relative expression ratio of DNA. These values in all kinetic classes began to raise at the first hour, including late genes. Therefore transcription of this kinetic class had already started before the onset of DNA replication, which was at 2 hour pi in wild-type virus. In us 1-KO mutant, this relationship also exists, but there is a delay both in the onset of transcription of late genes and DNA replication (2 hour pi and 6 hour pi, respectively). It would be really interesting to conduct the same experiments in another type of herpes virus, and study the relationship of late genes and DNA replication. Transcription of all the individual late genes started at 1 hour, therefore we cannot say that our findings derived from grouping the genes. In the literature, class of late gene is considered to contain so called leaky-late genes and late genes, and leaky-late genes are expressed before the DNA replication, while late genes are not. But our findings did not reveal this difference among late genes, and all the late genes were transcribed before the onset of DNA replication.

\section{Effect of viral load on gene expression}

In another study we found the difference between infecting with high amount of virus and low amount of virus. We have used the same technique as I mentioned earlier, focusing on the regulatory genes. Expression of ie180 and its antisense partner, AST was quite interesting. When cells were infected with low amount of virus, ie180 and AST were competitive and seemed to control, actually inhibit each other's transcription. When level of ie180 mRNA was high, amount of AST was low and vice versa. However, in cells infected with high amount of virus,level of ie180 was really high and inhibited the expression of AST. Based on this phenomenon we suggested a hypothesis about the infection strategy of the virus. According to our theory, when larger amount of virion infect the cell, virus has the ability to replicate and destroy the cell. Therefore the survival and propagation is insured. 
While during an infection with lower amount of virus, it is possible that virus cannot propagate immediately, and has to turn to latent state, instead of replicating, and choose another time to produce more virus, when the host is weaker.

\section{Recombinant viruses in electrophysiological measurements}

We have constructed modified viruses containing two different fluorescent proteins, which are different in color and time of maturation. The first color is green, and it derives from the GFP-containing expression cassette. The color appears 3 hours after the onset of infection, at a time point, when the cells can be considered living. Other color is red, and derives from the DsRed2 gene. The protein is present 10 hours after the onset of infection, and indicate the state of the cell, when it is not recommended to perform electrophysiological studies anymore because of the state of the cell. Using this virus it is possible to conduct experiments during healthy state of the virus. Activity sensor viruses contains an expression cassette encoding two fluorescent proteins and a $\mathrm{Ca} 2+$ sensitive troponin $\mathrm{C}$, which changes conformation if $\mathrm{Ca} 2+$ level raised and bound to it. Therefore wecould detect the neuronal activity in the retina. Combination of the two virus allowed us to detect the activity of the cells and define a time period while the cells are still alive and physiologically healthy.

\section{SUMMARY}

During my work we have developed an us 1 mutant PRV, which was not known in the literature. We have characterized DNA replication and gene expression compared to the wild-type virus. Us1 helped to initiate DNA replication on time, inhibited early gene expression and stimulated expression of late genes.

We also have compared infection with low and high amount of virus, the most important finding was the change in the regulatory genes (ie180 and ep0) and their antisense partner (LAT and AST) during the low-MOI and high-MOI infection. Genes and their antisense partners negatively control each other's transcription during low-MOI infection, while in high MOI the genes are expressed much higher extent and repress the antisense partners.

With help of using Timer, Activity sensor, and Combined viruses we can determine the physiologically intact state of cells, and measure the neuronal activity. 


\section{REFERENCES}

1. Aujeszky, A., A contagious disease, not readily distinguishable from rabies, with unknown origin (in Hungarian). Veterinarius, 1902. 25(12): p. 387-396.

2. Pomeranz, L.E., A.E. Reynolds, and C.J. Hengartner, Molecular biology of pseudorabies virus: impact on neurovirology and veterinary medicine. Microbiol Mol Biol Rev, 2005. 69(3): p. 462-500.

3. Sawitzky, D., Transmission, species specificity, and pathogenicity of Aujeszky's disease virus. Archives of Virology. Supplementum., 1997. 13: p. 201-206.

4. Peeters, B., et al., Pseudorabies virus envelope glycoproteins gp50 and gII are essential for virus penetration, but only gII is involved in membrane fusion. J Virol, 1992. 66(2): p. 894-905.

5. Gutekunst, D.E., et al., Isolation of pseudorabies virus from trigeminal ganglia of a latently infected sow. Am J Vet Res, 1980. 41(8): p. 1315-6.

6. Roizman, B., and D. M. Knipe., Herpes simplex viruses and their replication. 2001: p. 2399-2460.

7. Homa, F.L. and J.C. Brown, Capsid assembly and DNA packaging in herpes simplex virus. Rev Med Virol, 1997. 7(2): p. 107-122.

8. Sherman, G. and S.L. Bachenheimer, Characterization of Intranuclear Capsids Made by Ts Morphogenic Mutants of Hsv-1. Virology, 1988. 163(2): p. 471-480.

9. Ladin, B.F., M.L. Blankenship, and T. Benporat, Replication of Herpesvirus DNA .5. Maturation of Concatemeric DNA of Pseudorabies Virus to Genome Length Is Related to Capsid Formation. Journal of Virology, 1980. 33(3): p. 1151-1164.

10. Ben-Porat, T., and A. S. Kaplan., Molecular biology of pseudorabies virus. 1985: p. 105-173.

11. Fuchs, W., et al., The UL48 tegument protein of pseudorabies virus is critical for intracytoplasmic assembly of infectious virions. Journal of Virology, 2002. 76(13): p. 6729-6742.

12. Ihara, S., et al., Characterization of the immediate-early functions of pseudorabies virus. Virology, 1983. 131(2): p. 437-54. 
13. Martin, K.J., J.W. Lillie, and M.R. Green, Transcriptional activation by the pseudorabies virus immediate early protein. Genes Dev, 1990. 4(12B): p. 2376-82.

14. Campbell, M.E.M. and C.M. Preston, DNA-Sequences Which Regulate the Expression of the Pseudorabies Virus Major Immediate Early Gene. Virology, 1987. 157(2): p. 307-316.

15. $\mathrm{Wu}, \mathrm{C} . \mathrm{L}$. and K.W. Wilcox, The conserved DNA-binding domains encoded by the herpes simplex virus type 1 ICP4, pseudorabies virus IE180, and varicella-zoster virus ORF62 genes recognize similar sites in the corresponding promoters. J Virol, 1991. 65(3): p. 1149-59.

16. Cheung, A.K., Detection of pseudorabies virus transcripts in trigeminal ganglia of latently infected swine. J Virol, 1989. 63(7): p. 2908-13.

17. Cheung, A.K., Cloning of the latency gene and the early protein 0 gene of pseudorabies virus. J Virol, 1991. 65(10): p. 5260-71.

18. Ou, C.J., et al., Suppression of promoter activity of the LAT gene by IE180 of pseudorabies virus. Virus Genes, 2002. 25(3): p. 227-39.

19. Ono, E., et al., Pseudorabies virus (PRV) early protein 0 activates $P R V$ gene transcription in combination with the immediate-early protein IE180 and enhances the infectivity of PRV genomic DNA. Vet Microbiol, 1998. 63(2-4): p. 99-107.

20. Ho, T.Y., et al., Pseudorabies virus early protein 0 trans-activates the TATAassociated promoter by stimulating the transcription initiation. Virus Res, 1999. 61(1): p. 77-86.

21. Hagglund, R. and B. Roizman, Role of ICPO in the strategy of conquest of the host cell by herpes simplex virus 1. J Virol, 2004. 78(5): p. 2169-78.

22. Sacks, W.R. and P.A. Schaffer, Deletion mutants in the gene encoding the herpes simplex virus type 1 immediate-early protein ICPO exhibit impaired growth in cell culture. J Virol, 1987. 61(3): p. 829-39.

23. Banfield, B.W., et al., A chicken embryo eye model for the analysis of alphaherpesvirus neuronal spread and virulence. J Virol, 1998. 72(6): p. 4580-8.

24. Boldogkoi, Z., A. Braun, and I. Fodor, Replication and virulence of early protein 0 and long latency transcript deficient mutants of the Aujeszky's disease (pseudorabies) virus. Microbes Infect, 2000. 2(11): p. 1321-8. 
25. Tombacz, D., J.S. Toth, and Z. Boldogkoi, Effects of deletion of the early protein 0 gene of pseudorabies virus on the overall viral gene expression. Gene, 2012. 493(2): p. 235-42.

26. Schwartz, J.A., et al., UL54-null pseudorabies virus is attenuated in mice but productively infects cells in culture. Journal of Virology, 2006. 80(2): p. 769-784.

27. Fuchs, W., et al., Characterization of the replication origin $(\mathrm{Ori}(S))$ and adjoining parts of the inverted repeat sequences of the pseudorabies virus genome. J Gen Virol, 2000. 81(Pt 6): p. 1539-43.

28. Zhang, G. and D.P. Leader, The Structure of the Pseudorabies Virus Genome at the End of the Inverted Repeat Sequences Proximal to the Junction with the Short Unique Region. Journal of General Virology, 1990. 71: p. 2433-2441.

29. Tombacz, D., et al., Whole-genome analysis of pseudorabies virus gene expression by real-time quantitative RT-PCR assay. BMC Genomics, 2009. 10: p. 491.

30. Poffenberger, K.L., P.E. Raichlen, and R.C. Herman, In vitro characterization of a herpes simplex virus type 1 ICP22 deletion mutant. Virus Genes, 1993. 7(2): p. 17186.

31. Poffenberger, K.L., et al., A Herpes-Simplex Virus Type-1 Icp22 Deletion Mutant Is Altered for Virulence and Latency in-Vivo. Archives of Virology, 1994. 139(1-2): p. 111-119.

32. Holden, V.R., et al., ICP22 homolog of equine herpesvirus 1: expression from early and late promoters. J Virol, 1992. 66(2): p. 664-73.

33. Holden, V.R., et al., Identification and characterization of the ICP22 protein of equine herpesvirus 1. J Virol, 1994. 68(7): p. 4329-40.

34. Lu, H., et al., The Nonphosphorylated Form of Rna Polymerase-Ii Preferentially Associates with the Preinitiation Complex. Proceedings of the National Academy of Sciences of the United States of America, 1991. 88(22): p. 10004-10008.

35. Cadena, D.L. and M.E. Dahmus, Messenger-Rna Synthesis in Mammalian-Cells Is Catalyzed by the Phosphorylated Form of Rna Polymerase-Ii. Journal of Biological Chemistry, 1987. 262(26): p. 12468-12474.

36. Phatnani, H.P. and A.L. Greenleaf, Phosphorylation and functions of the RNA polymerase II CTD. Genes Dev, 2006. 20(21): p. 2922-36. 
37. Rice, S.A., et al., Rna-Polymerase-Ii Is Aberrantly Phosphorylated and Localized to Viral Replication Compartments Following Herpes-Simplex Virus-Infection. Journal of Virology, 1994. 68(2): p. 988-1001.

38. Long, M.C., et al., ICP22 and the UL13 protein kinase are both required for herpes simplex virus-induced modification of the large subunit of RNA polymerase II. Journal of Virology, 1999. 73(7): p. 5593-5604.

39. Rice, S.A., et al., Herpes-Simplex Virus Immediate-Early Protein Icp22 Is Required for Viral Modification of Host Rna-Polymerase-Ii and Establishment of the Normal Viral Transcription Program. Journal of Virology, 1995. 69(9): p. 5550-5559.

40. Spencer, C.A., M.E. Dahmus, and S.A. Rice, Repression of host RNA polymerase II transcription by herpes simplex virus type 1. J Virol, 1997. 71(3): p. 2031-40.

41. Leopardi, R., et al., Association of herpes simplex virus regulatory protein ICP22 with transcriptional complexes containing EAP, ICP4, RNA polymerase II, and viral DNA requires posttranslational modification by the $U(L) 13$ proteinkinase. J Virol, 1997. 71(2): p. 1133-9.

42. Markovitz, N.S. and B. Roizman, Small dense nuclear bodies are the site of localization of herpes simplex virus $1 U(L) 3$ and $U(L) 4$ proteins and of ICP22 only when the latter protein is present. Journal of Virology, 2000. 74(1): p. 523-528.

43. Durand, L.O., et al., The carboxyl-terminal domain of RNA polymerase II is phosphorylated by a complex containing cdk9 and infected-cell protein 22 of herpes simplex virus 1. Journal of Virology, 2005. 79(11): p. 6757-6762.

44. Advani, S.J., et al., The disappearance of cyclins $A$ and $B$ and the increase in activity of the G(2)/M-phase cellular kinase cdc2 in herpes simplex virus 1-infected cells require expression of the alpha22/U(S)1.5 and U(L)13 viral genes. J Virol, 2000. 74(1): p. 8-15.

45. Orlando, J.S., et al., The products of the herpes simplex virus type 1 immediate-early US1/US1.5 genes downregulate levels of S-phase-specific cyclins and facilitate virus replication in S-phase Vero cells. J Virol, 2006. 80(8): p. 4005-16.

46. Bastian, T.W. and S.A. Rice, Identification of Sequences in Herpes Simplex Virus Type 1 ICP22 That Influence RNA Polymerase II Modification and Viral Late Gene Expression. Journal of Virology, 2009. 83(1): p. 128-139. 
47. Bowman, J.J., et al., Transient expression of herpes simplex virus type 1 ICP22 represses viral promoter activity and complements the replication of an ICP22 null virus. J Virol, 2009. 83(17): p. 8733-43.

48. Kristensson, K. and Y. Olsson, Retrograde axonal transport of protein. Brain Res, 1971. 29(2): p. 363-5.

49. Kristensson, K., Morphological studies of the neural spread of herpes simplex virus to the central nervous system. Acta Neuropathol, 1970. 16(1): p. 54-63.

50. Ugolini, G., Advances in viral transneuronal tracing. J Neurosci Methods, 2010. 194(1): p. 2-20.

51. Kuypers, H.G.J.M. and G. Ugolini, Viruses as Transneuronal Tracers. Trends in Neurosciences, 1990. 13(2): p. 71-75.

52. Rotto-Percelay, D.M., et al., Transneuronal labeling of spinal interneurons and sympathetic preganglionic neurons after pseudorabies virus injections in the rat medial gastrocnemius muscle. Brain Res, 1992. 574(1-2): p. 291-306.

53. Ugolini, G., Transneuronal transfer of herpes simplex virus type 1 (HSV 1) from mixed limb nerves to the CNS. I. Sequence of transfer from sensory, motor, and sympathetic nerve fibres to the spinal cord. J Comp Neurol, 1992. 326(4): p. 527-48.

54. Loewy, A.D., Pseudorabies virus: A transneuronal tracer for neuroanatomical studies. 1995: p. 349-366.

55. Rinaman, L., J.P. Card, and L.W. Enquist, Spatiotemporal responses of astrocytes, ramified microglia, and brain macrophages to central neuronal infection with pseudorabies virus. J Neurosci, 1993. 13(2): p. 685-702.

56. Ugolini, G., Specificity of Rabies Virus as a Transneuronal Tracer of Motor Networks - Transfer from Hypoglossal Motoneurons to Connected 2nd-Order and HigherOrder Central-Nervous-System Cell Groups. Journal of Comparative Neurology, 1995. 356(3): p. 457-480.

57. Boldogkoi, Z., et al., Genetically timed, activity-sensor and rainbow transsynaptic viral tools. Nat Methods, 2009. 6(2): p. 127-30.

58. Graf, W., et al., Mapping the oculomotor system: the power of transneuronal labelling with rabies virus. European Journal of Neuroscience, 2002. 15(9): p. 15571562. 
59. Prasher, D.C., et al., Primary structure of the Aequorea victoria green-fluorescent protein. Gene, 1992. 111(2): p. 229-33.

60. Chalfie, M., et al., Green fluorescent protein as a marker for gene expression. Science, 1994. 263(5148): p. 802-5.

61. Kain, S.R., et al., Green fluorescent protein as a reporter of gene expression and protein localization. Biotechniques, 1995. 19(4): p. 650-5.

62. Matz, M.V., et al., Fluorescent proteins from nonbioluminescent Anthozoa species. Nat Biotechnol, 1999. 17(10): p. 969-73.

63. Heim, N., et al., Improved calcium imaging in transgenic mice expressing a troponin C-based biosensor. Nat Methods, 2007. 4(2): p. 127-9.

64. Soong, R., et al., Quantitative reverse transcription-polymerase chain reaction detection of cytokeratin 20 in noncolorectal lymph nodes. Clin Cancer Res, 2001. 7(11): p. 3423-9.

65. Cohen, J.I., et al., The varicella-zoster virus open reading frame 63 latencyassociated protein is critical for establishment of latency. J Virol, 2004. 78(21): p. 11833-40.

66. Sommer, M.H., et al., Mutational analysis of the repeated open reading frames, ORFs 63 and 70 and ORFs 64 and 69, of varicella-zoster virus. J Virol, 2001. 75(17): p. 8224-39.

67. Tombacz, D., J.S. Toth, and Z. Boldogkoi, Deletion of the virion host shut: off gene of pseudorabies virus results in selective upregulation of the expression of early viral genes in the late stage of infection. Genomics, 2011. 98(1): p. 15-25.

68. Kramer, T., et al., Proteomic characterization of pseudorabies virus extracellular virions. J Virol, 2011. 85(13): p. 6427-41.

69. Loret, S., G. Guay, and R. Lippe, Comprehensive characterization of extracellular herpes simplex virus type 1 virions. J Virol, 2008. 82(17): p. 8605-18.

70. David G. Anders, J.A.K., and Gregory S. Pari., Human Herpesviruses. Cambridge University Press, 2007.

71. Bailey, T.L. and C. Elkan, Fitting a mixture model by expectation maximization to discover motifs in biopolymers. Proc Int Conf Intell Syst Mol Biol, 1994. 2: p. 28-36. 
72. Aaron W. Kolb, T.R.S., David W. Dyer, and Curtis R. Brandt, Sequence Variation in the Herpes Simplex Virus US1 Ocular Virulence Determinant. Investigate Ophthalmology \& Visual Science, 2011. 10.

73. Baiker, A., et al., The immediate-early 63 protein of Varicella-Zoster virus: analysis of functional domains required for replication in vitro and for T-cell and skin tropism in the SCIDhu model in vivo. J Virol, 2004. 78(3): p. 1181-94.

74. O'Toole, J.M., et al., Mutation of the protein tyrosine kinase consensus site in the herpes simplex virus 1 alpha22 gene alters ICP22 posttranslational modification. Virology, 2003. 305(1): p. 153-67.

75. Bontems, S., et al., Phosphorylation of varicella-zoster virus IE63 protein by casein kinases influences its cellular localization and gene regulation activity. $\mathrm{J}$ Biol Chem, 2002. 277(23): p. 21050-60.

76. Batchelor, A.H. and P. O'Hare, Regulation and cell-type-specific activity of a promoter located upstream of the latency-associated transcript of herpes simplex virus type 1. J Virol, 1990. 64(7): p. 3269-79.

77. Vlcek, C., et al., Pseudorabies virus immediate-early gene overlaps with an oppositely oriented open reading frame: characterization of their promoter and enhancer regions. Virology, 1990. 179(1): p. 365-77.

\section{ACKNOWLEDGEMENTS}

Foremost, I would like to express my sincere gratitude to my advisor Prof. ZsoltBoldogkői for the continuous support of my PhD study and research, for his patience, motivation, enthusiasm, and immense knowledge. His guidance helped me in all the time of research and writing of this thesis.

Besides my advisor, I would like to thank my fellow labmates, DóraTombácz, JuditTóth, IstvánPrazsák, PálPetrovszki, EmesePásti, NándorPóka for their useful advice and help during my work. Also I would like to thank my graduate student, Beáta Berta for her time and enthusiasm. 
I am very thankfulour technicians, for the constant patience and reliability, KatalinCsonka, KisapátiEdéné and CsillaPapdi. I could not even imagine being efficient without their help in the lab. Gabriella Teleki, our secretary made my life much easier in helping all the administration.

Also, I would like to thank for the Doctoral School of Multidisciplinary Medicine for the useful lessons during the three years. 